\title{
A Reduced-Order Controller Considering High-Order Modal Information of High-Rise Buildings for AMD Control System with Time-Delay
}

\author{
Zuo-Hua Li, ${ }^{1}$ Chao-Jun Chen, ${ }^{1}$ Jun Teng, ${ }^{1}$ Wei-Hua Hu, ${ }^{1}$ Hou-Bing Xing, ${ }^{2}$ and Ying Wang ${ }^{3}$ \\ ${ }^{1}$ School of Civil and Environment Engineering, Shenzhen Graduate School, Harbin Institute of Technology, Shenzhen 518055, China \\ ${ }^{2}$ China Construction 4th Engineering Division Corp., Ltd., South China Branch, Guangzhou 510660, China \\ ${ }^{3}$ Department of Civil and Environmental Engineering, University of Surrey, Guildford GU2 7XH, UK \\ Correspondence should be addressed to Jun Teng; tengj@hit.edu.cn
}

Received 15 October 2016; Accepted 6 December 2016; Published 19 January 2017

Academic Editor: Paulo B. Gonçalves

Copyright ( 2017 Zuo-Hua Li et al. This is an open access article distributed under the Creative Commons Attribution License, which permits unrestricted use, distribution, and reproduction in any medium, provided the original work is properly cited.

\begin{abstract}
Time-delays of control force calculation, data acquisition, and actuator response will degrade the performance of Active Mass Damper (AMD) control systems. To reduce the influence, model reduction method is used to deal with the original controlled structure. However, during the procedure, the related hierarchy information of small eigenvalues will be directly discorded. As a result, the reduced-order model ignores the information of high-order mode, which will reduce the design accuracy of an AMD control system. In this paper, a new reduced-order controller based on the improved Balanced Truncation (BT) method is designed to reduce the calculation time and to retain the abandoned high-order modal information. It includes high-order natural frequency, damping ratio, and vibration modal information of the original structure. Then, a control gain design method based on Guaranteed Cost Control (GCC) algorithm is presented to eliminate the adverse effects of data acquisition and actuator response time-delays in the design process of the reduced-order controller. To verify its effectiveness, the proposed methodology is applied to a numerical example of a ten-storey frame and an experiment of a single-span four-storey steel frame. Both numerical and experimental results demonstrate that the reduced-order controller with GCC algorithm has an excellent control effect; meanwhile it can compensate time-delays effectively.
\end{abstract}

\section{Introduction}

Active Mass Damper (AMD) can be used to control the dynamic response of highly flexible building horizontally under strong wind or earthquake [1-4]. At present, several problems restrict the development of AMD control system, such as slow calculation speed and long time-delay $[5,6]$. They mainly resulted from data acquisition, control force calculation, and actuator response.

Regarding high-rise building structures, the excessive number of degrees of freedom causes the fact that the order of the designed controller based on the original model will be extremely large, and the long control force calculation time induces the fact that the control force is too difficult to fulfill the requirement of real-time control. Hence, it is necessary to build a reduced-order controller to reduce calculation workload and decrease time-delay [7]. Model reduction [8] is a process that a more complex model will be transformed for a low-order model that meets the requirements of engineering precision. For instance, a dynamic condensation method was proposed for high-rise buildings with Active Tuned Mass Damper (ATMD) control system; the analysis results showed the proposed method was efficient for the reduced-order modeling and reduced calculation time and workload [9]. The dynamic model reduction method was applied to obtain a reduced-order model of an experimental high-rise building with an AMD control system, and numerical simulations showed the low-order controller could be used availably to mitigate the vibration [10]. Balanced Truncation (BT) method $[11,12]$ is more widely used to complete model reduction of high-rise buildings $[9,13]$. According to eigenvalues' size of state vectors in a high-rise building, BT method will be used 
to reorder these state vectors to form the internal equilibrium model. Partial state vectors that correspond to the small eigenvalues will be omitted. They include high-order modal information of the original structure. However, the omitted state vectors will decrease the accuracy of model reduction method and reduce the control effect of this controller. It is necessary to reconsider high-order modal information in the design process of a reduced-order controller.

In addition to control force calculation time-delay, the compensation design method of the time-delays of data acquisition and actuator response should be considered. Obviously, conventional methods of control include poleassignment method and linear quadratic regulator cannot be used in time-delay systems. For instance, Linear Quadratic Regulator (LQR) [14] is a suitable control strategy for highrise buildings, but it requires an accurate mathematical model. If parameter perturbation or time-delay exists in a closed-loop system, its stability is difficult to be guaranteed. Linear Matrix Inequality (LMI) [15] approach is widely used to analyze the stability of time-delay systems [16-19] and to design a feedback controller with compensation gain [20-23]. Although compensation gain needs to guarantee the performance of systems with time-delay, Guaranteed Cost Control (GCC) algorithm [24] is a special LQR control method that is widely used in the fields of electronics, aerospace, mechanical engineering, and automation, and it combines the performance and robustness of nonlinear systems with time-delay $[25,26]$. In order to implement GCC for a high-rise building, a key step is to solve a positive-definite solution of Riccati matrix equations. Previously, this problem is based on the Riccati equation method, and several key parameters should be determined in advance. However, methods for searching for the optimal values of these parameters are still lacking. The only method of artificially determined parameters is conservative, and the Riccati equation is solved by iterative methods; it means that the convergence is not guaranteed [2730]. Combined with LMI approach, the Riccati matrix equations could be solved easily. As a result, the time-delay compensation controller with GCC algorithm can be designed for high-rise buildings based on LMI approach.

In this paper, a low-order controller based on improved BT method is proposed and the structural high-order modal information is considered, and the influence of transfer functions and orders of a low-order model on the control system's performance is analyzed. As a result, the performance of this system can be guaranteed and the order of the controlled structure can be reduced in maximum extent. The design problem of a time-delay compensation control gain based on GGC algorithm can be expressed as a group of nonlinear matrix inequalities. It can be further transformed into a group of linear matrix inequalities (LMIs) through variable substitution method [31]. Finally, the design of the reducedorder controller with GCC algorithm for high-rise buildings is performed to compensate its long time-delay. A numerical example of ten-storey frame and an experiment of a single span four-storey steel frame will be presented to validate the effectiveness of the proposed method.

\section{The Design Method of Reduced-Order Controller with GCC Algorithm}

2.1. Reduced-Order Controller Design by Improved BT Method. The state-space equation of an AMD control systems is

$$
\begin{aligned}
& \dot{Z}(t)=A Z(t)+B U(t), \\
& Y(t)=C Z(t)+D U(t),
\end{aligned}
$$

where $A, B, C$, and $D$ are the state matrix, the control matrix, the state output matrix, and the direct transmission matrix, respectively. $Z$ and $Y$ are the state vector and the output vector, respectively. $U$ includes control force and input excitation.

When control force and input excitation are considered separately, (1) can be described as

$$
\begin{aligned}
& \dot{Z}(t)=A Z(t)+B_{2} u(t)+B_{1} w(t), \\
& Y(t)=C Z(t)+D_{2} u(t)+D_{1} w(t),
\end{aligned}
$$

where $u$ and $w$ are the control force and the input excitation, respectively. $A, B_{1}, B_{2}, C, D_{1}$, and $D_{2}$ can be expressed as

$$
\begin{aligned}
& A=\left[\begin{array}{cc}
0 & I \\
-M^{-1} K & -M^{-1} C
\end{array}\right], \\
& B_{1}=\left[\begin{array}{c}
0 \\
-M^{-1} B_{w}
\end{array}\right], \\
& B_{2}=\left[\begin{array}{c}
0 \\
-M^{-1} B_{s}
\end{array}\right], \\
& C=\left[\begin{array}{c}
I \\
0 \\
-M^{-1} K \\
0 \\
0 \\
-M^{-1} C \\
0
\end{array}\right], \\
& D_{1}=\left[\begin{array}{c}
0 \\
0 \\
-M^{-1} B_{w} \\
0
\end{array}\right], \\
& D_{2}=\left[\begin{array}{c}
0 \\
0 \\
-M^{-1} B_{s} \\
1
\end{array}\right],
\end{aligned}
$$

where $M, C$, and $K$ are the mass, damping, and stiffness matrix of an AMD control system, respectively. $B_{s}$ and $B_{w}$ are the location matrices of control force and strong wind, respectively.

The balanced realization system can be obtained by transforming the state-space equation of the stable system by BT method. Define

$$
Z(t)=T Z_{b}(t)
$$


where $T$ is the transform matrix. $Z_{b}$ is the state vector of the balanced realization system.

By substituting (4) into (2), the state-space equation of the balanced realization system is

$$
\begin{aligned}
& \dot{Z}_{b}(t)=A_{b} Z_{b}(t)+B_{b 2} u(t)+B_{b 1} w(t), \\
& Y_{b}(t)=C_{b} Z_{b}(t)+D_{b 2} u(t)+D_{b 1} w(t),
\end{aligned}
$$

where $A_{b}=T^{-1} A T, B_{b 2}=T^{-1} B_{2}, B_{b 1}=T^{-1} B_{1}, C_{b}=C T$, $D_{b 2}=D_{2}$, and $D_{b 1}=D_{1}$. lated:

According to [32], the transform matrix $T$ can be calcu-

$$
T=L_{c} V S^{-1 / 2},
$$

where $V$ and $S$ are the orthogonal and the positive diagonal matrices that can be obtained by applying the singular value decomposition technique for the matrix $L_{o}^{T} L_{c} . L_{c}$ and $L_{o}$ are the lower triangular matrix of the controllability and the observability matrices decomposed by Cholesky.

Then the matrix $S$ can be described as

$$
S=\operatorname{diag}\left(\sigma_{1}, \sigma_{2}, \ldots, \sigma_{n}\right),
$$

where $\sigma_{i}$ is the diagonal elements that reflect the controllability and observability of the state vector.

The diagonal elements $\sigma_{i}$ were rearranged in descending order. When $\sigma_{r+1} \ll \sigma_{r}, r$ is the reserved order and is twice the number of the structure vibration modes; it means that the states $Z_{r+1} \sim Z_{n}$ corresponding to the eigenvalues $\sigma_{r+1} \sim \sigma_{n}$ have lower performance of controllability and observability. Only the states $Z_{1} \sim Z_{r}$ are retained in the balanced realization system. The state-space equation of this system is

$$
\begin{gathered}
\dot{Z}_{b r}(t)=A_{b r} Z_{b r}(t)+B_{b r 2} u(t)+B_{b r 1} w(t), \\
Y_{b r}(t)=C_{b r} Z_{b r}(t)+D_{b r 2} u(t)+D_{b r 1} w(t),
\end{gathered}
$$

where $A_{b r}=A_{b}(1: r, 1: r), B_{b r 2}=B_{b 2}(1: r,:), B_{b r 1}=E_{b 1}(:$, $1: r), C_{b r}=C_{b}(:, 1: r), D_{b r 2}=D_{b 2}$, and $D_{b r 1}=D_{b 1}$.

Equation (8) can be described as block matrix:

$$
\begin{aligned}
\left\{\begin{array}{c}
\dot{Z}_{b r}(t) \\
\dot{Z}_{b l}(t)
\end{array}\right\}= & {\left[\begin{array}{cc}
A_{b r} & A_{b 12} \\
A_{b 21} & A_{b 22}
\end{array}\right]\left\{\begin{array}{c}
Z_{b r}(t) \\
Z_{b l}(t)
\end{array}\right\}+\left\{\begin{array}{c}
B_{b r 2} \\
B_{b l 2}
\end{array}\right\} u(t) } \\
& +\left\{\begin{array}{c}
B_{b r 1} \\
B_{b l 1}
\end{array}\right\} w(t), \\
Y_{b}(t)= & {\left[\begin{array}{ll}
C_{b r} & C_{b l}
\end{array}\right] \cdot\left\{\begin{array}{c}
Z_{b r}(t) \\
Z_{b l}(t)
\end{array}\right\}+D_{b 2} u(t) } \\
& +D_{b 1} w(t)
\end{aligned}
$$

where $Z_{b r}$ and $Z_{b l}$ are the retained and abandoned state vectors of the balanced realization system, respectively.

Block matrix of (4) is

$$
\left\{\begin{array}{c}
Z_{b r}(t) \\
Z_{b l}(t)
\end{array}\right\}=\left[\begin{array}{ll}
\left(T^{-1}\right)_{11} & \left(T^{-1}\right)_{12} \\
\left(T^{-1}\right)_{21} & \left(T^{-1}\right)_{22}
\end{array}\right]\left\{\begin{array}{c}
Z_{r}(t) \\
Z_{l}(t)
\end{array}\right\},
$$

where $Z_{r}$ and $Z_{l}$ are the retained and abandoned state vectors corresponding to the original system.

Substituting (10) into (9) leads to

$$
\begin{aligned}
\left\{\begin{array}{c}
\dot{Z}_{b r}(t) \\
\dot{Z}_{b l}(t)
\end{array}\right\}= & {\left[\begin{array}{cc}
A_{1} & A_{2} \\
A_{3} & A_{4}
\end{array}\right]\left\{\begin{array}{c}
Z_{r}(t) \\
Z_{l}(t)
\end{array}\right\}+\left\{\begin{array}{c}
B_{b r 2} \\
B_{b l 2}
\end{array}\right\} u(t) } \\
& +\left\{\begin{array}{c}
B_{b r 1} \\
B_{b l 1}
\end{array}\right\} w(t) \\
Y_{b}(t)= & {\left[\begin{array}{ll}
C_{1} & C_{2}
\end{array}\right]\left\{\begin{array}{c}
Z_{r}(t) \\
Z_{l}(t)
\end{array}\right\}+D_{b 2} u(t) } \\
& +D_{b 1} w(t)
\end{aligned}
$$

where $A_{1}=A_{b r}\left(T^{-1}\right)_{11}+A_{b 12}\left(T^{-1}\right)_{21}, A_{2}=A_{b r}\left(T^{-1}\right)_{12}+$ $A_{b 12}\left(T^{-1}\right)_{22}, \quad A_{3}=A_{b 21}\left(T^{-1}\right)_{11}+A_{b 22}\left(T^{-1}\right)_{21}, \quad A_{4}=$ $A_{b 21}\left(T^{-1}\right)_{12}+A_{b 22}\left(T^{-1}\right)_{22}, C_{1}=C_{b r}\left(T^{-1}\right)_{11}+C_{b l}\left(T^{-1}\right)_{21}$, and $C_{2}=C_{b r}\left(T^{-1}\right)_{12}+C_{b l}\left(T^{-1}\right)_{22}$.

The reduced-order model obtained by BT method retains the first few modes of the original structure that is continuous and with large modal mass participating ratio. Modal mass participation ratio is a coefficient to characterize the contribution of structural vibration mode to the structural response. Under an input excitation, the low-order modal mass participation ratio of a flexible structure is close to 1 , and the high-order modal mass participation ratio is relatively small. Therefore, the contribution of high-order modes to the structural response can be ignored, in order to fulfill the requirement of engineering accuracy (e.g., the minimum retained modal mass participation ratio of a flexible building can be defined as $90 \%[33,34])$. According to $(10), Z_{b l}$ is written as

$$
Z_{b l}(t)=\left(T^{-1}\right)_{21} \cdot Z_{r}(t)+\left(T^{-1}\right)_{22} \cdot Z_{l}(t)=0 .
$$

From (12), $Z_{l}$ can be written as

$$
Z_{l}(t)=-\left[\left(T^{-1}\right)_{22}\right]^{-1} \cdot\left(T^{-1}\right)_{21} \cdot Z_{r}(t) .
$$

Since some state messages of the balanced realization system in $Z_{l}$ are directly discarded, this will result in the inaccuracy of this system.

Substituting (13) into (10) leads to

$$
\begin{aligned}
Z_{b r}(t)= & {\left[\left(T^{-1}\right)_{11}-\left(T^{-1}\right)_{12} \cdot\left(\left(T^{-1}\right)_{22}\right)^{-1} \cdot\left(T^{-1}\right)_{21}\right] } \\
& \cdot Z_{r}(t)=T_{r} Z_{r}(t) .
\end{aligned}
$$

According to (14), $\dot{Z}_{b r}(t)$ that is the derivative of $Z_{b r}(t)$ with respect to time is expressed as

$$
\dot{Z}_{b r}(t)=T_{r} \dot{Z}_{r}(t)
$$

Depending on (11), $\dot{Z}_{b l}(t)$ can be expressed as

$$
\begin{gathered}
\dot{Z}_{b l}(t)=A_{3} \cdot Z_{r}(t)+A_{4} \cdot Z_{l}(t)+B_{b l 2} \cdot u(t)+B_{b l 1} \\
\cdot w(t)=0 .
\end{gathered}
$$


From (16), $Z_{l}$ is

$$
Z_{l}(t)=-A_{4}^{-1}\left[A_{3} \cdot Z_{r}(t)+B_{b l 2} \cdot u(t)+B_{b l 1} \cdot w(t)\right] .
$$

Substituting (15) and (17) into (11) leads to

$$
\begin{aligned}
\dot{Z}_{r}(t)= & T_{r}^{-1}\left(A_{1}-A_{2} A_{4}^{-1} A_{3}\right) Z_{r}(t) \\
& +T_{r}^{-1}\left(B_{b r 2}-A_{2} A_{4}^{-1} B_{b l 2}\right) u(t) \\
& +T_{r}^{-1}\left(B_{b r 1}-A_{2} A_{4}^{-1} B_{b l 1}\right) w(t), \\
Y_{r}(t)= & \left(C_{1}-C_{2} A_{4}^{-1} A_{3}\right) Z_{r}(t) \\
& +\left(D_{b 2}-C_{2} A_{4}^{-1} B_{b l 2}\right) u(t) \\
& +\left(D_{b 1}-C_{2} A_{4}^{-1} B_{b l 1}\right) w(t),
\end{aligned}
$$

where $A_{r}=T_{r}^{-1}\left(A_{1}-A_{2} A_{4}^{-1} A_{3}\right), B_{r 2}=T_{r}^{-1}\left(B_{b r 2}-\right.$ $\left.A_{2} A_{4}^{-1} B_{b l 2}\right), B_{r 1}=T_{r}^{-1}\left(B_{b r 1}-A_{2} A_{4}^{-1} B_{b l 1}\right), C_{r}=C_{1}-$ $C_{2} A_{4}^{-1} A_{3}, D_{r 2}=D_{b 2}-C_{2} A_{4}^{-1} B_{b l 2}$, and $D_{r 1}=D_{b 1}-$ $\mathrm{C}_{2} A_{4}^{-1} B_{b l 1}$.

Equation (18) displays a reduced-order model by improved BT method and can be simplified as

$$
\begin{aligned}
& \dot{Z}_{r}(t)=A_{r} Z_{r}(t)+B_{r 2} u(t)+B_{r 1} w(t), \\
& Y_{r}(t)=C_{r} Z_{r}(t)+D_{r 2} u(t)+D_{r 1} w(t) .
\end{aligned}
$$

The truncation error of the reduced-order model shown as (19) can be defined as

$$
\|e\|_{\infty} \leq 2\left(\sigma_{r+1}+\sigma_{r+2}+\cdots+\sigma_{n}\right) .
$$

Depending on inequality (20), the model reduction accuracy of the reduced-order model is

$$
\eta=1-\frac{\|e\|_{\infty}}{\left(2 \sum_{i=1}^{n} \sigma_{i}\right)} \geq \eta_{\text {min }}
$$

where $\eta_{\min }=90 \%$ is the minimum model reduction accuracy.

2.2. Time-Delay Compensation Control Gain Design by GCC Algorithm. Although the reduced-order controller design method in Section 2.1 can reduce the adverse effects of time-delay of control force calculation, the time-delay of the control system also includes other aspects. Therefore, it is necessary to design a compensation control gain to compensate other kinds of time-delays that includes the time of data acquisition and actuator response. The GCC algorithm is a suitable LQR controller design method. When the time-delay is considered, the control force of the reduced-order control system is

$$
u_{d}(t)=-G_{r} Z_{r}(t-d),
$$

where $G_{r}$ is a closed-loop feedback gain matrix and $d$ is a time-delay.

By substituting (22) into (19), the state equation of the system when input excitation is not considered temporarily is

$$
\dot{Z}_{r}(t)=A_{r} Z_{r}(t)-B_{r 2} G_{r} Z_{r}(t-d) .
$$

Defining $\bar{A}_{r}=-B_{r 2} G_{r}$. If there exist symmetric positivedefinite matrices $P, S \in R^{n \times n}$, then

$$
\left[\begin{array}{cc}
A_{r}^{T} P+P A_{r}+S & P \bar{A}_{r} \\
\bar{A}_{r}^{T} P & -S
\end{array}\right]<0 .
$$

Hence, system (23) is asymptotically stable. Lyapunov function is defined as follows:

$$
V\left(Z_{t}\right)=Z_{r}^{T}(t) P Z_{r}(t)+\int_{t-d}^{t} Z_{r}^{T}(\tau) S Z_{r}(\tau) d \tau
$$

where $Z_{t}=Z_{r}(t+\alpha), \alpha \in[-d, 0], V\left(Z_{t}\right)$ is a positive-definite matrix and $\dot{V}\left(Z_{t}\right)$ is the derivative of $V\left(Z_{t}\right)$ with respect to time. According to the algorithms of the transport matrix,

$$
\begin{gathered}
\dot{V}\left(Z_{t}\right)=\dot{Z}_{r}^{T}(t) P Z_{r}(t)+Z_{r}^{T}(t) P \dot{Z}_{r}(t)+Z_{r}^{T}(t) \\
\cdot S Z_{r}(t)-Z_{r}^{T}(t-d) S Z_{r}(t-d)=\left[\begin{array}{c}
Z_{r}(t) \\
Z_{r}(t-d)
\end{array}\right]^{T} \\
\cdot\left[\begin{array}{cc}
A_{r}^{T} P+P A_{r}+S & P \bar{A}_{r} \\
\bar{A}_{r}^{T} P & -S
\end{array}\right]\left[\begin{array}{c}
Z_{r}(t) \\
Z_{r}(t-d)
\end{array}\right] .
\end{gathered}
$$

According to inequality (24), $\dot{V}\left(Z_{t}\right)$ is a negative-definite function. Based on Lyapunov stability theory [35], it proves that the control system (23) is asymptotically stable.

When control force and input excitation are all considered, the reduced-order control system shown as (19) with time-delay can be described as

$$
\begin{aligned}
\dot{Z}_{r}(t)= & A_{r} Z_{r}(t)+\bar{A}_{r} Z_{r}(t-d)+B_{r 1} w(t) \\
& +B_{r 2} u(t) .
\end{aligned}
$$

If the control force $u(t)=-G_{r} Z_{r}$, the closed-loop system is

$$
\begin{aligned}
\dot{Z}_{r}(t)= & \left(A_{r}-B_{r 2} G_{r}\right) Z_{r}(t)+\bar{A}_{r} Z_{r}(t-d) \\
& +B_{r 1} w(t) .
\end{aligned}
$$

The performance index of system (28) can be defined as

$$
\begin{aligned}
J & =\int_{0}^{\infty}\left(Z_{r}^{T} Q Z_{r}+u_{r}^{T} R u_{r}\right) d t \\
& =\int_{0}^{\infty}\left\{Z_{r}^{T}\left[Q+\left(-G_{r}\right)^{T} R\left(-G_{r}\right)\right] Z_{r}\right\} d t
\end{aligned}
$$

where weight matrices $Q$ and $R$ are the two important parameters in LQR algorithm and the selection of weight matrices reflects the importance of the security and economy in AMD control systems. 
According to inequality (24), if there exist symmetric positive-definite matrices $P, S \in R^{n \times n}$, then

$$
\left[\begin{array}{cc}
\left(A_{r}-B_{r 2} G_{r}\right)^{T} P+P\left(A_{r}-B_{r 2} G_{r}\right)+S+Q+\left(-G_{r}\right)^{T} R\left(-G_{r}\right) & P \bar{A}_{r} \\
\bar{A}_{r}^{T} P & -S
\end{array}\right]<0 .
$$

System (28) is asymptotically stable. According to inequality (30),

$$
\begin{gathered}
{\left[\begin{array}{cc}
\left(A_{r}-B_{r 2} G_{r}\right)^{T} P+P\left(A_{r}-B_{r 2} G_{r}\right)+S & P \bar{A}_{r} \\
\bar{A}_{r}^{T} P & -S
\end{array}\right]} \\
<\left[\begin{array}{cc}
-\left[Q+\left(-G_{r}\right)^{T} R\left(-G_{r}\right)\right] & 0 \\
0 & 0
\end{array}\right]<0 .
\end{gathered}
$$

Depending on (26), inequality (31) is premultiplying

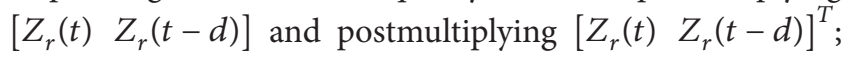
then

$$
Z_{r}^{T}\left[Q+\left(-G_{r}\right)^{T} R\left(-G_{r}\right)\right] Z_{r}<-\dot{V}\left(Z_{t}\right)
$$

By integrating inequality (32), the performance index of a system with time-delay satisfies

$$
\begin{aligned}
J & =\int_{0}^{\infty}\left\{Z_{r}^{T}\left[Q+\left(-G_{r}\right)^{T} R\left(-G_{r}\right)\right] Z_{r}\right\} d t \\
& \leq\left[Z_{0}^{T} P Z_{0}+\int_{-d}^{0} \varphi^{T}(t) S \varphi(t) d t\right] .
\end{aligned}
$$
then

Inequality (30) is pre- and postmultiplying $\operatorname{diag}\left\{P^{-1}, I\right\}$;

$$
\left[\begin{array}{cc}
H_{r} & \bar{A}_{r} \\
\bar{A}_{r}^{T} & -S
\end{array}\right]<0
$$

where $X=P^{-1}$ and $H_{r}=X\left(A_{r}-B_{r 2} G_{r}\right)^{T}+\left(A_{r}-B_{r 2} G_{r}\right) X+$ $X S X+X\left[Q+\left(-G_{r}\right)^{T} R\left(-G_{r}\right)\right] X$.

Variable substitution method can be used for solving this problem. Defining $W=-G_{r} X$. From Schur's complement [36], inequality (34) can be expressed as

$$
\left[\begin{array}{ccccc}
\widetilde{H}_{r} & \bar{A}_{r} & X & W^{T} & X \\
\bar{A}_{r}^{T} & -S & 0 & 0 & 0 \\
X & 0 & -Q^{-1} & 0 & 0 \\
W & 0 & 0 & -R^{-1} & 0 \\
X & 0 & 0 & 0 & -S^{-1}
\end{array}\right]<0
$$

where $\widetilde{H}_{r}=A_{r} X+B_{r 2} W+\left(A_{r} X+B_{r 2} W\right)^{T}$. Inequality (35) is pre- and postmultiplying $\operatorname{diag}\left\{I, S^{-1}, I, I, I\right\}$, and $V=S^{-1}$. Inequality (35) can be expressed as

$$
\left[\begin{array}{ccccc}
\widetilde{H}_{r} & \bar{A}_{r} V & X & W^{T} & X \\
V \bar{A}_{r}^{T} & -V & 0 & 0 & 0 \\
X & 0 & -Q^{-1} & 0 & 0 \\
W & 0 & 0 & -R^{-1} & 0 \\
X & 0 & 0 & 0 & -V
\end{array}\right]<0
$$

where the optimal solutions of $X^{\prime}, W^{\prime}$, and $V^{\prime}$ are obtained through the LMI toolbox of MATLAB. The optimal feedback gain matrix of the controller is

$$
G_{r}=-W^{\prime}\left(X^{\prime}\right)^{-1}
$$

Then the state feedback control law is

$$
u(t)=W^{\prime}\left(X^{\prime}\right)^{-1} Z(t) .
$$

The reduced-order controller with GCC algorithm is shown in Figure 1. The state-space equation of the reducedorder system is depicted by the dashed box in the figure, and the symbol inside the solid box in the figure represents the time-delay compensation control gain obtained by GCC algorithm.

\section{Numerical Verification}

3.1. Transfer Function Analysis of the Reduced-Order Model. In this paper, a ten-storey frame shown in Figure 2 has been constructed for numerical analysis. The height and total mass of this structure are $33 \mathrm{~m}$ and 892.9 tons, respectively. The height of each floor is $3.3 \mathrm{~m}$, and the height and the width of the beams along the minor-axis and the major-axis are $500 \mathrm{~mm} \times 250 \mathrm{~mm}$ (Beam 1 and Beam 2). The height and the width of Beam 3 are $450 \mathrm{~mm} \times 200 \mathrm{~mm}$, and the dimensions of the columns are $500 \mathrm{~mm} \times 500 \mathrm{~mm}$.

The lumped mass method is used to build the mass matrix for the structure. A unit force is applied to each particle floor of the structure, and then the displacement at each floor is obtained and combined into the flexibility matrix. The stiffness matrix can be easily obtained, as the inverse of the flexibility matrix. The AMD control device is assumed to be installed on the 8th floor and is only used to control the horizontal vibration along the minor axis. Key parameters of AMD are listed in Table 1. Structural frequencies and modal 


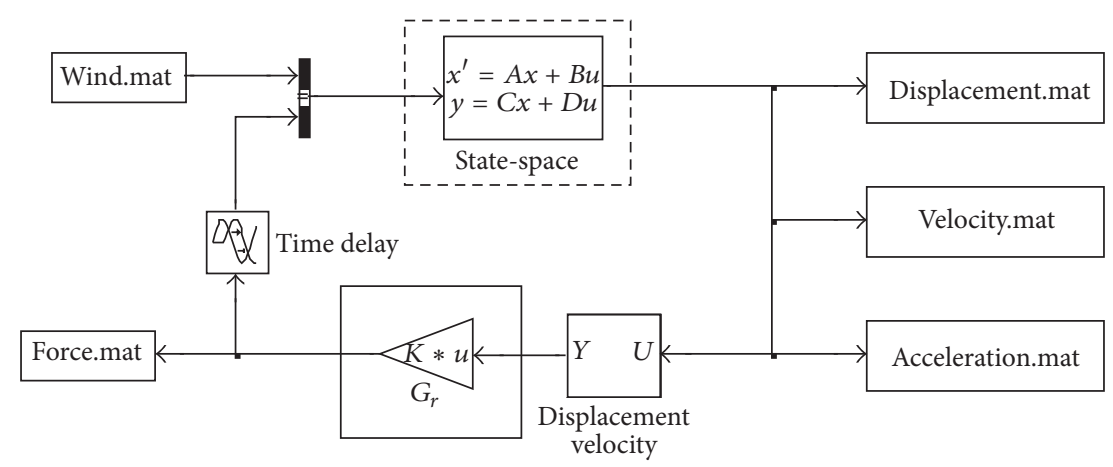

FIGURE 1: Simulink block diagram of the reduced-order controller with GCC algorithm.

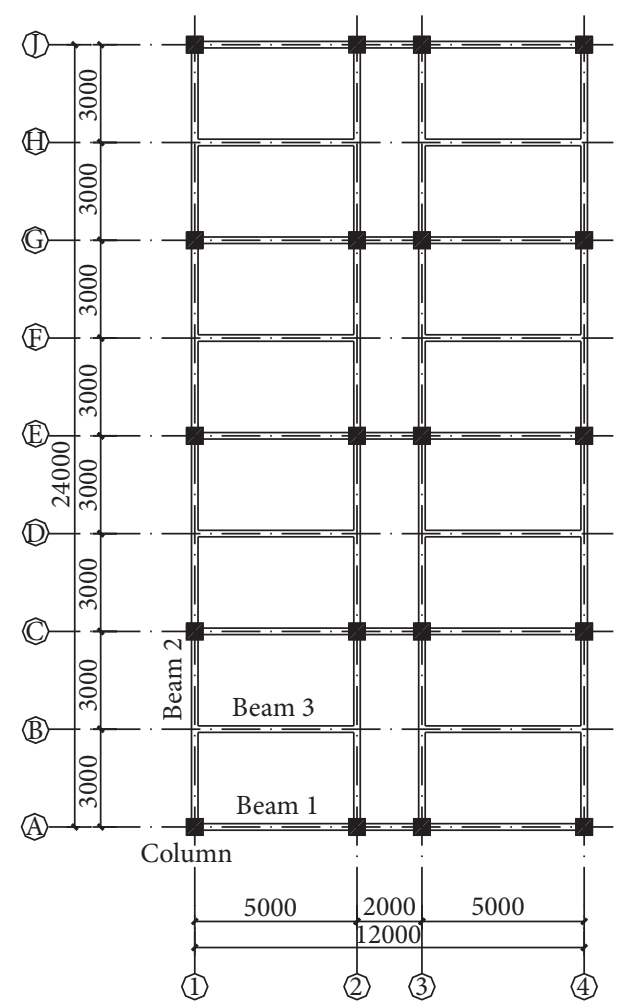

Figure 2: The plan of each floor.

TABLE 1: Key parameters of AMD.

\begin{tabular}{lc}
\hline Index & AMD \\
\hline Auxiliary mass $(\mathrm{kg})$ & 4000 \\
Effective stroke $(\mathrm{m})$ & \pm 1.1 \\
Maximum driving force $(\mathrm{kN})$ & 27.5 \\
\hline
\end{tabular}

mass participation ratios [37] of the ten-storey frame are calculated using the model constructed in MATLAB and listed in Table 2.

The reduced-order controller can be designed by Simulink toolbox in MATLAB. In this paper, the improved BT method is used to reduce the orders of the original model, and its characteristics of the transfer functions are compared with
TABLE 2: Modal mass participation ratios and natural frequencies of the frame.

\begin{tabular}{lccc}
\hline $\begin{array}{l}\text { Vibration } \\
\text { mode }\end{array}$ & $\begin{array}{c}\text { Modal mass } \\
\text { participation ratio }\end{array}$ & Sum & Frequency $(\mathrm{Hz})$ \\
\hline 1 & 0.7940 & 0.7940 & 0.9009 \\
2 & 0.0985 & 0.8925 & 2.8744 \\
3 & 0.0410 & 0.9335 & 5.3248 \\
4 & 0.0237 & 0.9572 & 8.4175 \\
5 & 0.0156 & 0.9728 & 12.2549 \\
\hline
\end{tabular}

the reduced-order model by classical BT method. Regarding the above ten-storey frame structure, its displacement and acceleration transfer functions of the top floor with different orders are shown in Figures 3 and 4. The input and output of these transfer functions are all top floor. In this figure, ORM means the structure retains the original model (20 orders), while $r$ is retained orders of $4,8,12$, and 16 . Considering the structural frequency range, the part between $0.01 \mathrm{~Hz}$ and $100 \mathrm{~Hz}$ is shown in the figures.

Figures 3 and 4 show that, with the increase of the retained order, the difference between the original model and the reduced-order model by the above two BT methods will become smaller. From Figures 3(a) and 4(a), the displacement transfer functions of the two reduced-order models are basically consistent with the original model in low frequency. From Figures 3(b), 3(d), 4(b), and 4(d), since acceleration response is mainly affected by the higher modes and the reduced-order model by classical BT method discards some structural information of high-order modes, its acceleration transfer function is not well consistent with the original model in low frequency. Nevertheless, since the improved BT method presented in this paper can retain this discarded information, not only the displacement but also the acceleration transfer function of the improved model is basically consistent with the original model in low frequency, meaning that the reduced-order model by improved BT method can better reflect the dynamic characteristics of the original model in low frequency.

3.2. Mode Number Influence Analysis of the Reduced-Order Model. The necessity of the reduced-order controller by 


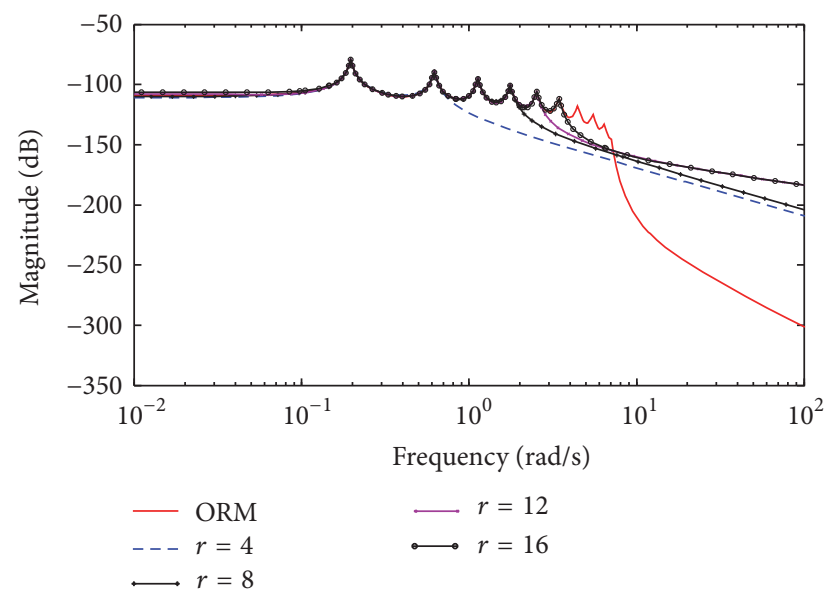

(a)

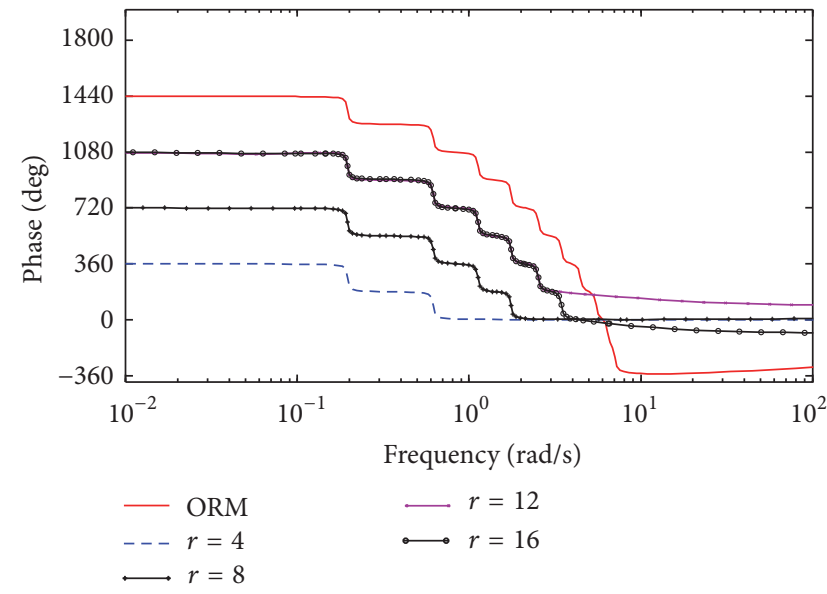

(c)

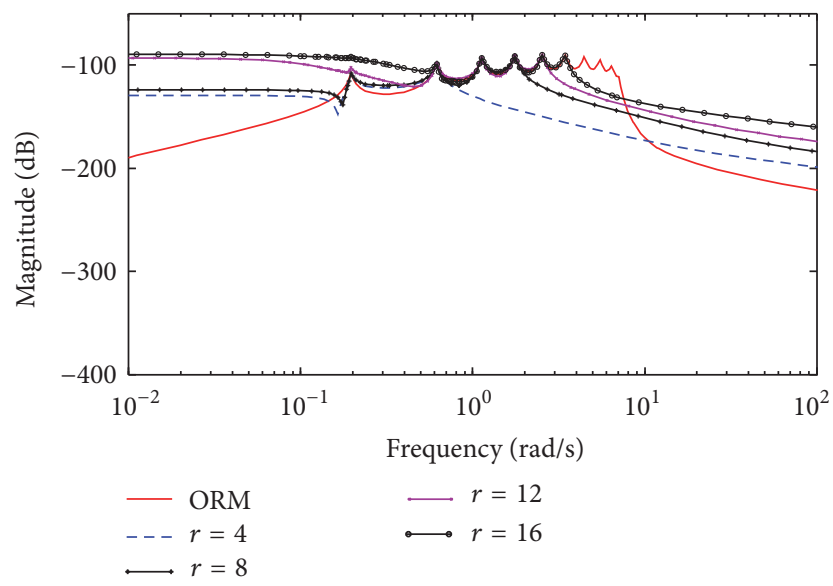

(b)

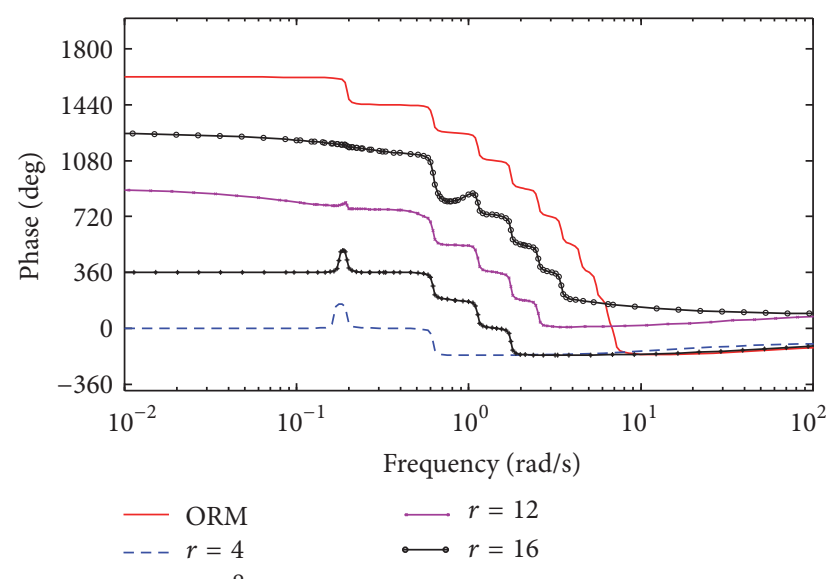

(d)

FIGURE 3: Comparison of transfer functions of the reduced-order model by classical BT method. (a) Magnitude and (c) phase of the displacement transfer functions. (b) Magnitude and (d) phase of the acceleration transfer functions.

improved BT method is verified by a numerical example of the above ten-storey frame. From Table 2, the first three orders of the modal mass participation ratios of the frame are 0.9335 which is greater than $90 \%$, meaning that these orders contribute a large portion of the resultant structural dynamic response. The minimum order of the reduced-order model is defined as 6 , and the maximum mode number is defined as 8 , meaning that the maximum order is 16 .

Fluctuating wind is caused by the irregularity of the wind, and its intensity is changed with time. Its short period and dynamic characteristics lead to the random vibration of the structure. In the paper, a ten-year return period fluctuating wind speed with Davenport spectrum will be generated, and mixed autoregressive-moving average (MARMA) model [38] is proposed to simulate the stochastic process. The wind load is applied to the ten-storey frame, and it can be calculated by the following equation:

$$
P_{i}=\rho \bar{V}(z) u_{i}(z, t) \mu_{s} A,
$$

where $P_{i}$ is the fluctuating wind load at $i$ th floor and $\rho$ is the air density. $\bar{V}(z)$ is the average wind speed at $i$ th floor. $u_{i}$ is the fluctuating wind speed that is associated with height and time. $\mu_{s}$ and $A$ are the shape coefficient of a building and the area facing the wind, respectively.

Under the above wind load, the model reduction accuracy, the 8th floor's control effects (defined as the difference between controlled and uncontrolled responses), and the AMD parameters of different reduced-order models are listed in Table 3.

Table 3 shows that since the reduced-order model by improved BT method presented in this paper can effectively retain the structural high-order modal information, when the retained orders are a range from 6 to 16, the maximum variations of the displacement and acceleration control effects are $0.0049 \%$ and $0.0395 \%$, and the maximum variations of the AMD parameters are only $0.0003 \mathrm{~m}$ and $0.0003 \mathrm{kN}$, meaning that the control effects and AMD parameters are all relatively stable. As a result, the order of the controlled structure can be reduced by the improved BT method in maximum extent.

The above ten-storey frame structure is recommended to retain 6 orders. The analysis whether the reduced-order system can effectively save the calculation time is given in 


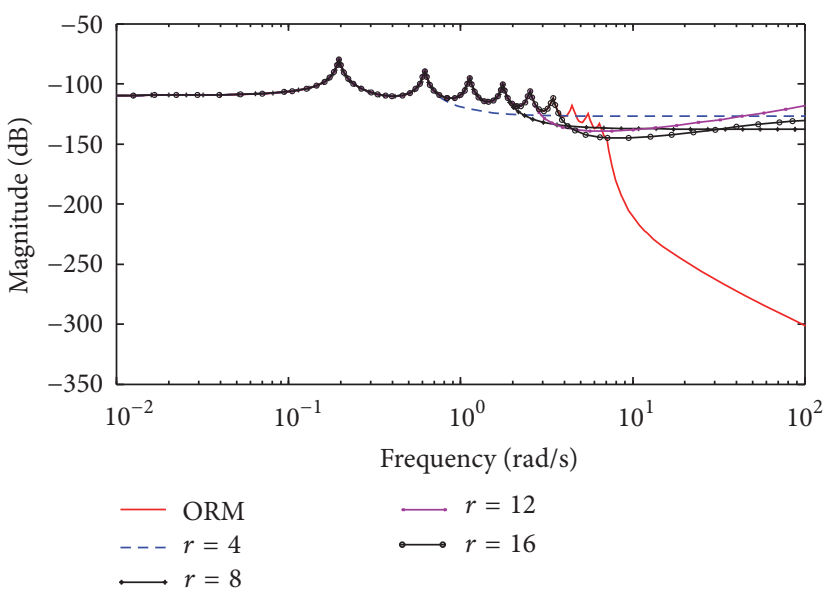

(a)

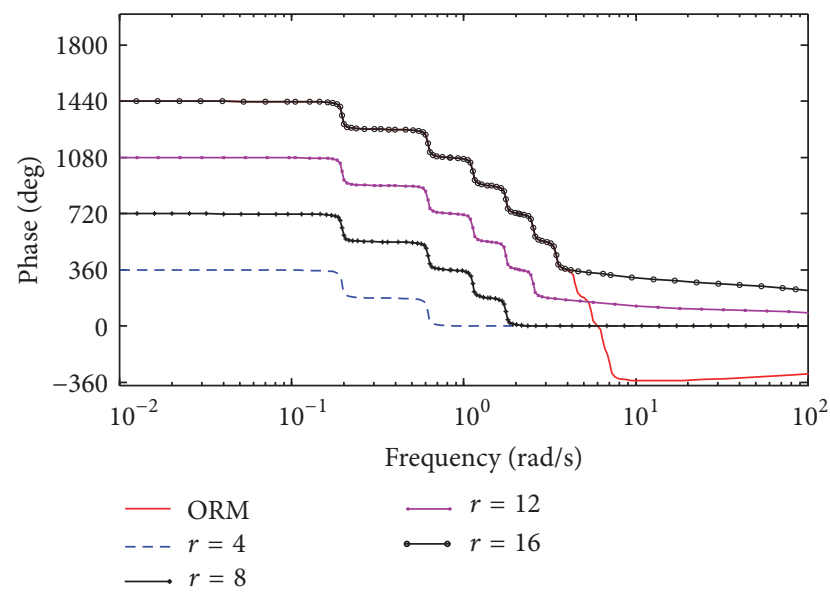

(c)

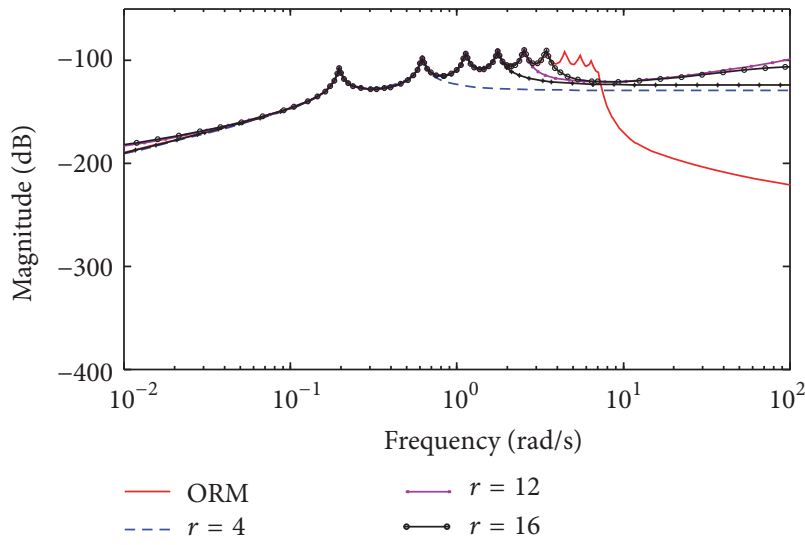

(b)

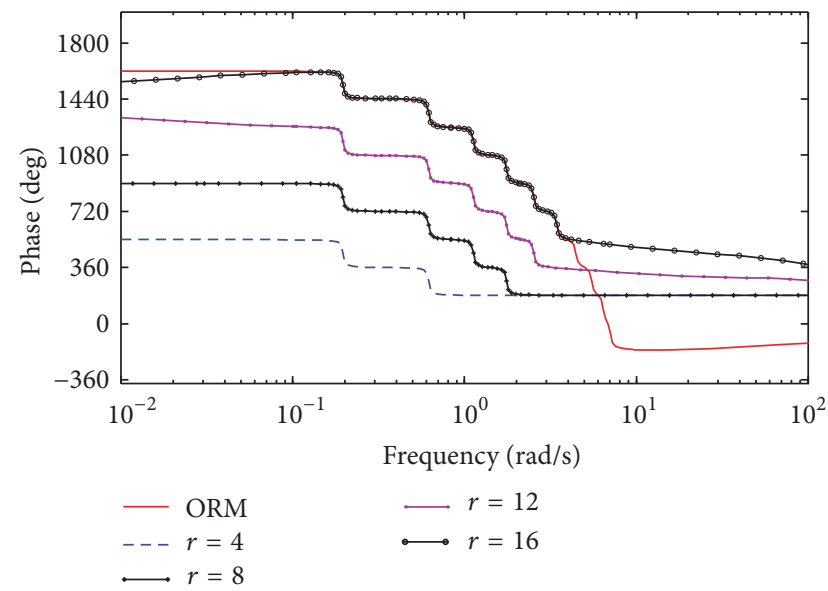

(d)

FIGURE 4: Comparison of transfer functions of the reduced-order model by improved BT method. (a) Magnitude and (c) phase of the displacement transfer functions. (b) Magnitude and (d) phase of the acceleration transfer functions.

TABLE 3: Comparison of the performances of control system under different orders.

\begin{tabular}{lccccc}
\hline Order & $\begin{array}{c}\text { Model reduction } \\
\text { accuracy }(\%)\end{array}$ & $\begin{array}{c}\text { Displacement control } \\
\text { effect (\%) }\end{array}$ & $\begin{array}{c}\text { Acceleration control } \\
\text { effect (\%) }\end{array}$ & AMD strokes (m) & AMD control forces (kN) \\
\hline 6 & 80.94 & 34.4379 & 33.7841 & 0.0540 & 8.8061 \\
8 & 84.02 & 34.4401 & 33.8022 & 0.0541 & 8.8062 \\
10 & 86.82 & 34.4425 & 33.8152 & 0.0543 & 8.8064 \\
12 & 89.54 & 34.4428 & 33.8073 & 0.0543 & 8.8064 \\
14 & 92.21 & 34.4410 & 33.8201 & 0.0543 & 8.8063 \\
16 & 94.86 & 34.4404 & 33.8236 & 0.0543 & 8.8063 \\
\hline
\end{tabular}

this paper, and calculation times of the reduced-order system under different orders are shown in Table 4. The calculation time of the reduced-order system under 6 orders is regarded as the comparison target, and then the accelerated ratios of calculation time of the reduced-order system under different orders are obtained in the table.
Table 4 shows that, (1) with the increase of the retained order, the calculation time of control force will become larger. (2) The maximum retained order of the reduced-order system is 16 , and its calculation time of control force is $3.9583 \times$ $10^{-6} \mathrm{~s}$. Nevertheless, the control force's calculation time of the reduced-order system with 6 retained orders is only 


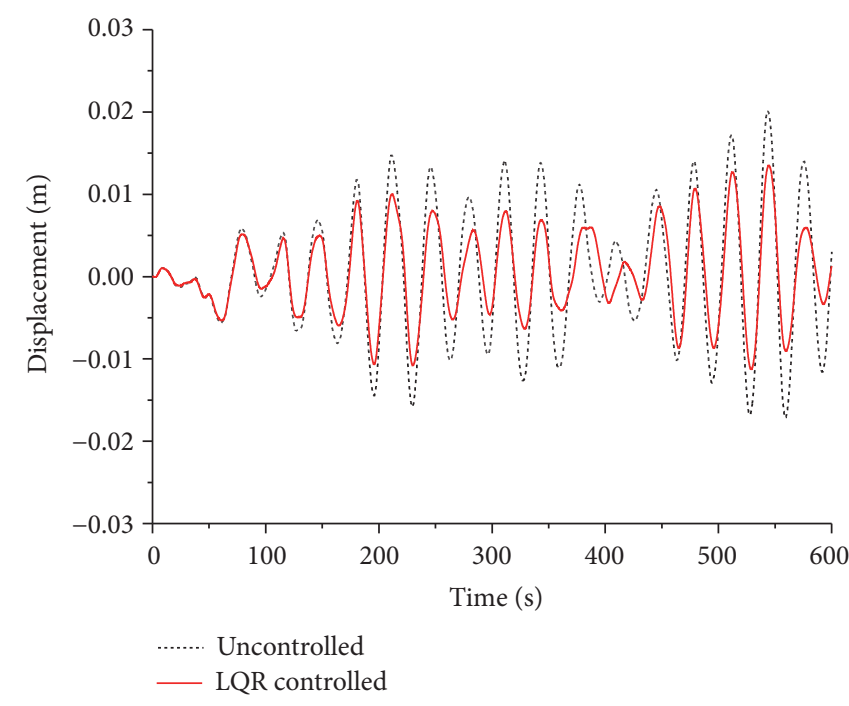

(a)

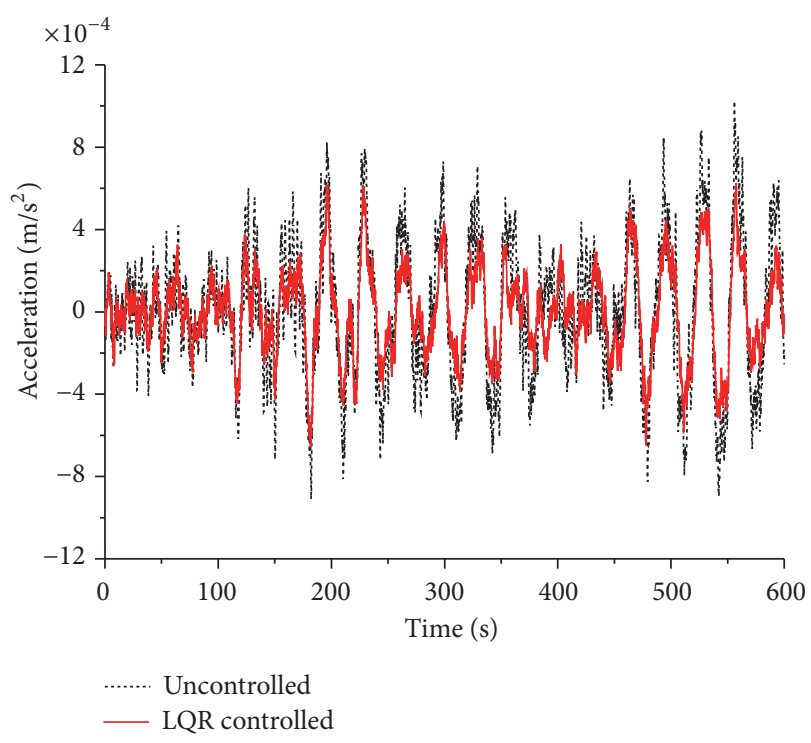

(c)

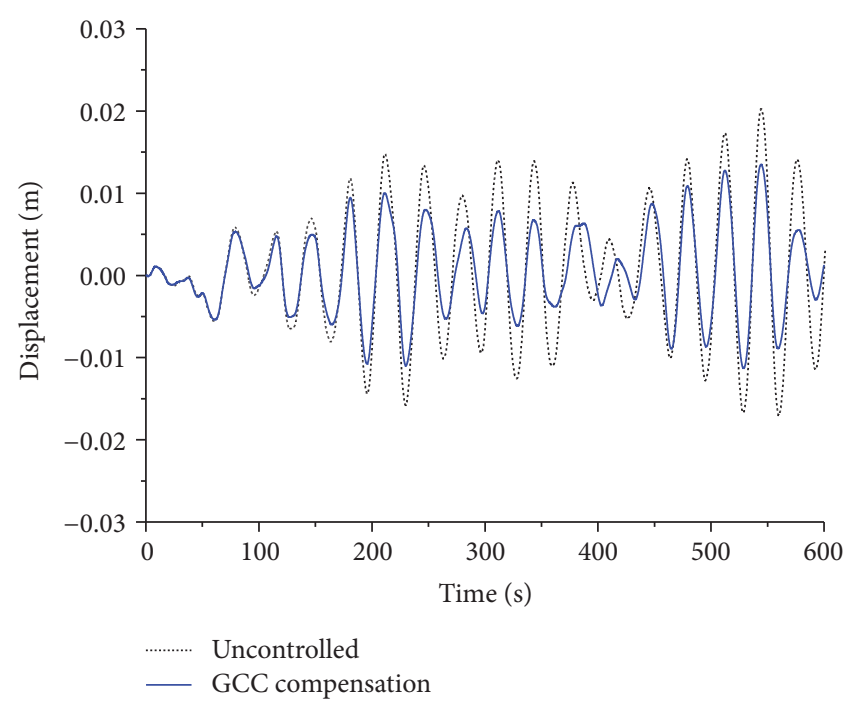

(b)

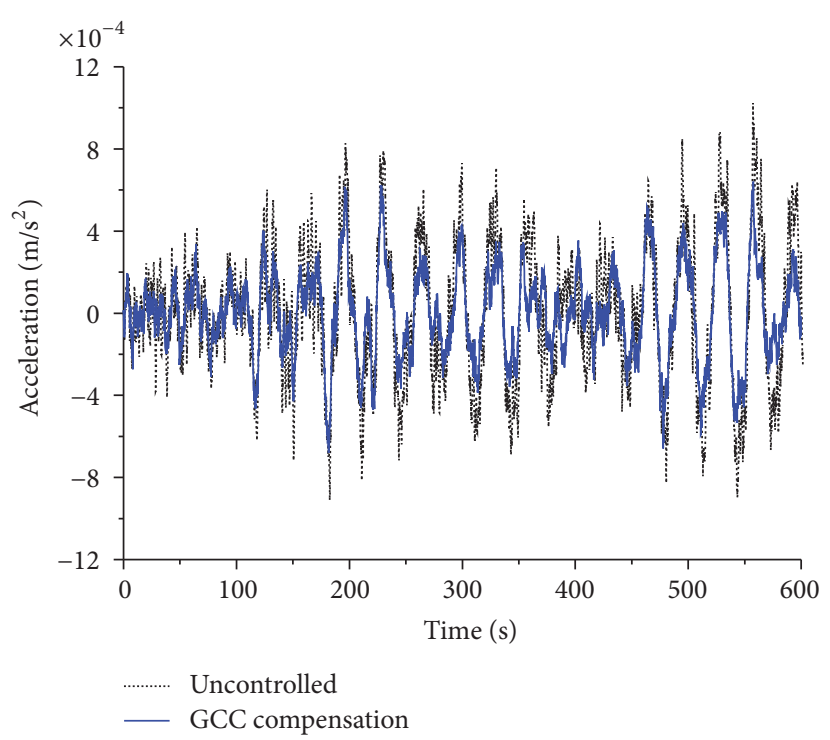

(d)

FIGURE 5: Comparison of structural responses to 8th floor. (a) and (c) Under uncontrolled and controlled by LQR algorithm without timedelay. (b) and (d) Under uncontrolled and controlled with GCC compensation.

TABLE 4: Comparison of the calculation time of control force under different orders

\begin{tabular}{lcc}
\hline Order & Calculation time $\left(\times 10^{-6} \mathrm{~s}\right)$ & Accelerated ratios $(\%)$ \\
\hline 6 & 2.9167 & - \\
8 & 3.1250 & 6.6656 \\
10 & 3.3750 & 13.5793 \\
12 & 3.5833 & 18.6030 \\
14 & 3.7917 & 23.0767 \\
16 & 3.9583 & 26.3143 \\
\hline
\end{tabular}

$2.9167 \times 10^{-6} \mathrm{~s}$. The accelerated ratio between two reducedorder systems is $26.3143 \%$. It is proved that the reduced-order controller can not only guarantee the performance of the control system (from Table 3), but also effectively reduce the control force calculation time.

3.3. Performance Analysis of the Reduced-Order Controller with GCC Algorithm. A reduced-order controller with GCC algorithm for the ten-storey frame is designed to compare with the classical controller based on LQR algorithm, and GCC compensation stands for a system with time-delay and a designed reduced-order compensation controller with GCC algorithm. Under a ten-year return period wind load, the structural responses and the AMD parameters of different control systems with and without time-delay (time-delay in this paper is assumed as $0.5 \mathrm{~s}$ ) are shown in Figures 5 and 6. The corresponding control effects and AMD parameters are listed in Table 5. 


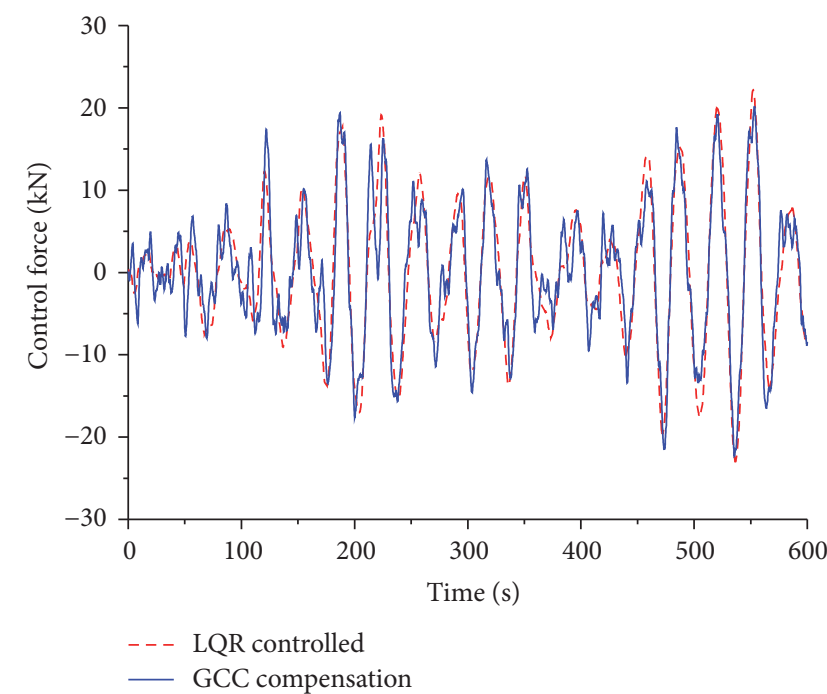

(a)

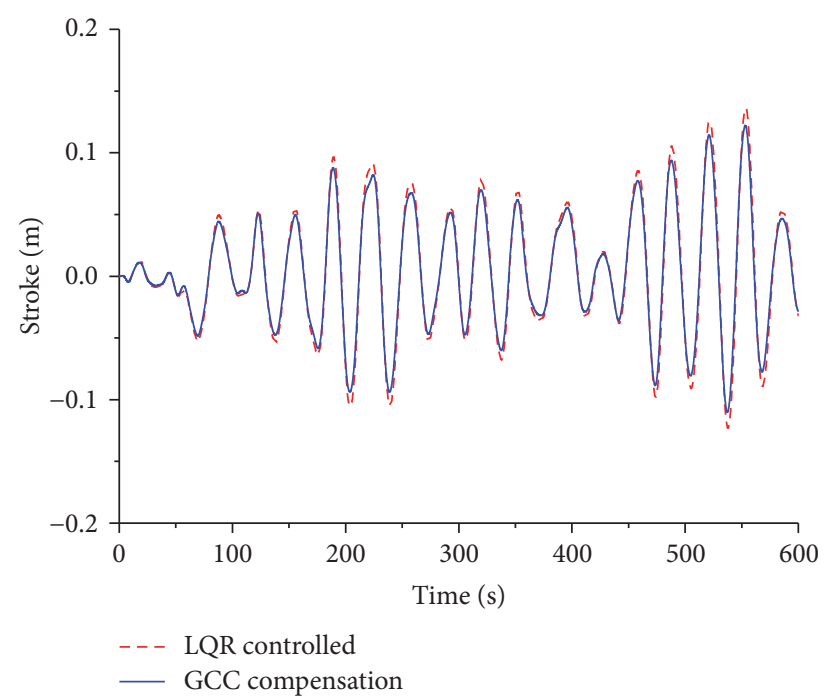

(b)

FIGURE 6: Comparison of AMD parameters, (a) AMD control forces, and (b) AMD strokes.

TABLE 5: Comparison of control effects (\%) and AMD parameters of different control systems.

\begin{tabular}{|c|c|c|c|c|}
\hline Floor & Index & $\begin{array}{l}\text { Without time-delay } \\
\text { and classical LQR } \\
\text { algorithm (\%) }\end{array}$ & $\begin{array}{l}\text { With time-delay and } \\
\text { classical LQR } \\
\text { algorithm }(\%) \\
\end{array}$ & $\begin{array}{c}\text { With time-delay and } \\
\text { GCC compensation } \\
(\%)\end{array}$ \\
\hline \multirow{3}{*}{ 8th } & Displacement (m) & 34.8069 & -14.4568 & 34.4633 \\
\hline & Velocity (m/s) & 35.3560 & -15.1235 & 34.8744 \\
\hline & Acceleration $\left(\mathrm{m} / \mathrm{s}^{2}\right)$ & 34.5862 & -14.1547 & 33.5514 \\
\hline \multirow{3}{*}{ 9th } & Displacement (m) & 34.7768 & -14.3658 & 34.4344 \\
\hline & Velocity $(\mathrm{m} / \mathrm{s})$ & 34.7299 & -14.1469 & 34.2723 \\
\hline & Acceleration $\left(\mathrm{m} / \mathrm{s}^{2}\right)$ & 29.0512 & -19.5269 & 28.1406 \\
\hline \multirow{3}{*}{ 10th } & Displacement (m) & 34.7414 & -14.4756 & 34.3974 \\
\hline & Velocity $(\mathrm{m} / \mathrm{s})$ & 34.2854 & -14.1975 & 33.8494 \\
\hline & Acceleration $\left(\mathrm{m} / \mathrm{s}^{2}\right)$ & 29.4658 & -19.3269 & 28.7185 \\
\hline \multicolumn{2}{|c|}{ Control force $(\mathrm{kN})$} & 8.4381 & 8.9587 & 8.1838 \\
\hline \multicolumn{2}{|c|}{ Stroke $(\mathrm{m})$} & 0.0524 & 0.0695 & 0.0464 \\
\hline
\end{tabular}

From Figures 5 and 6 and Table 5, (1) the system with time-delay based on the classical LQR algorithm is divergent. (2) After GCC compensating the time-delay, the control effects and AMD parameters of the system with time-delay are close to the system without time-delays. In particular, the maximum variations of the displacement, velocity, and acceleration control effects are only $0.3440 \%, 0.4816 \%$, and $1.0348 \%$. Therefore, the reduced-order controller with GCC algorithm can effectively compensate the time-delay and decrease the structural response. (3) The reduced-order controller with GCC algorithm can maintain the stability of AMD parameters and are consistent with the system without timedelay. The AMD parameters of the system only change by $0.2543 \mathrm{~N}$ and $0.0060 \mathrm{~m}$.

\section{Experimental Verification}

Figure 7 shows an experimental system of a four-storey steel frame with an AMD control device installed on the fourth floor [39]. A servo motor can acquire the forces from an EtherCAT bus system and was used to add these forces to control the structure. The AMD system mainly consisted of a servo motor, servo controller, an EtherCAT bus system, a dSPACE system with a type of DS1103, and a computer.

To validate the efficiency of the developed method, the reduced-order controller by improved BT method is applied to the experimental system. The full-order model of the experimental system with AMD is 10 , and the retained orders of the reduced-order model are recommended to be 4,6 , 


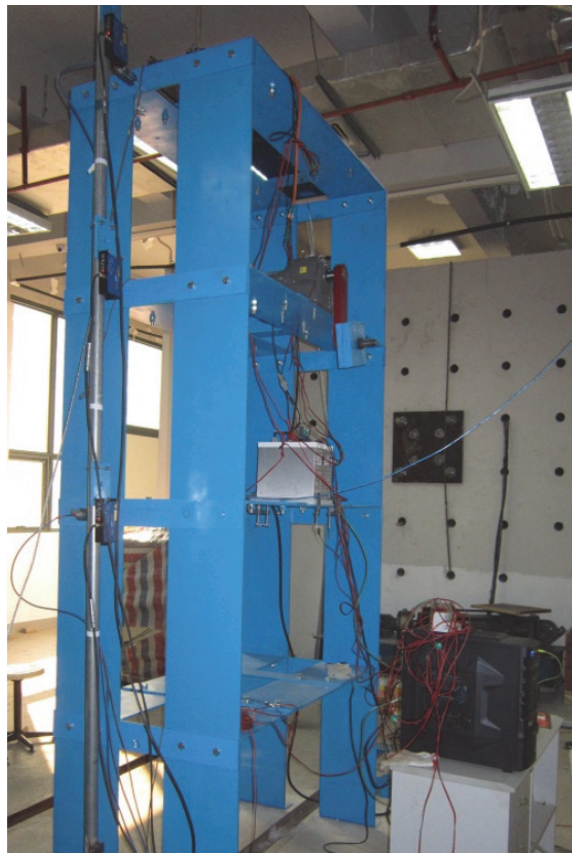

(a)

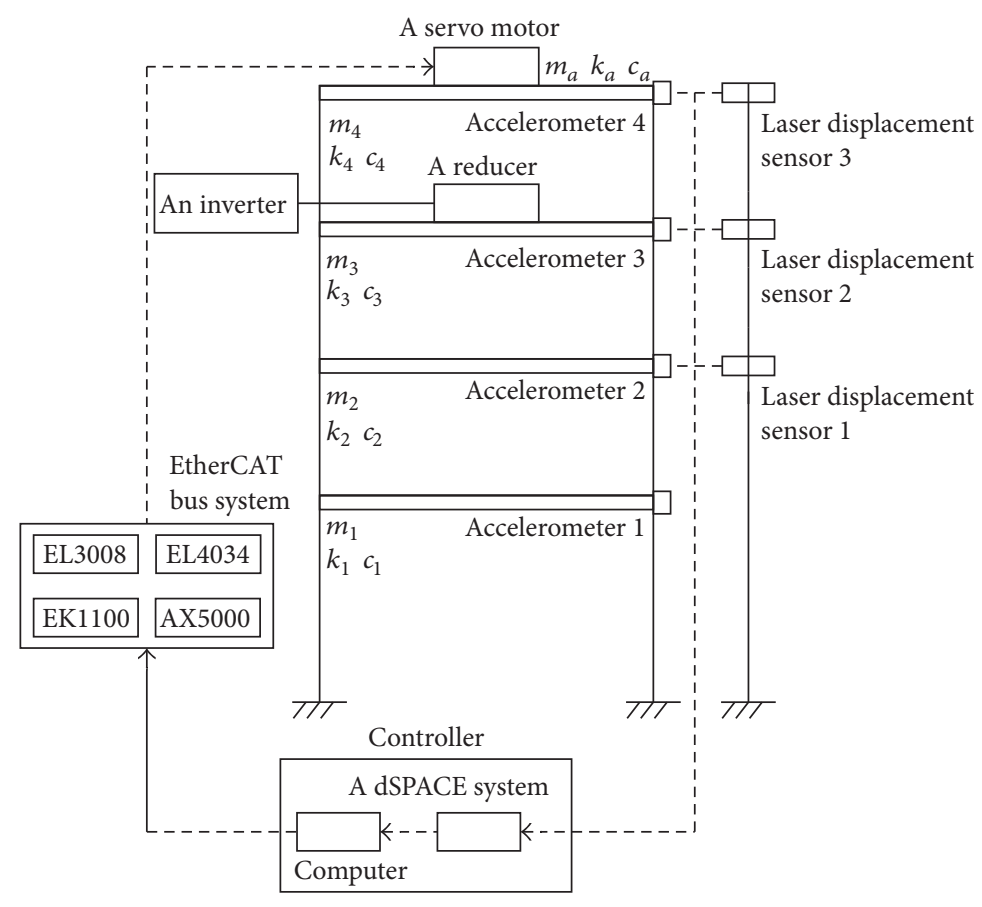

(b)

Figure 7: Pictures of the steel frame structure. (a) Practicality. (b) Exhibition.

and 8 , respectively. The loading frequency of the system is $1 \mathrm{~Hz}$; that is, the peak value of the corresponding excitation force is $45.89 \mathrm{~N}$, and the wave form of this force is sinusoidal. Under the above excitation load, the control effects and AMD parameters of different control systems are listed in Table 6, and the structural responses (includes displacement and acceleration) to 4 th floor of different control systems are shown in Figures 8 and 9. AMD parameters of the 4-order system are shown in Figure 10.

From Figures 8-10 and Table 6, (1) as the retained orders of the experimental system are a range from 4 to 10 , the displacement and acceleration control effects and AMD parameters are all relatively stable, meaning that the performance of the reduced-order controller is consistent with the fullorder controller. Therefore, the retained order 4 of the controlled structure can be reduced by the improved BT method in maximum extent. (2) Because of the interaction between the AMD system and the structure as well as the coupling between the horizontal and vertical vibrations of the structure, the structural responses do not completely obey the change regulation of a sine-wave under a sinusoidal load. (3) The acceleration control needs high frequency control force that will stimulate the structural high-order modes, and AMD device is placed in the fourth floor of the structure. Due to above two reasons, the control effect of third floor is an opposite high-order phase with the fourth floor and significantly less than the control effects of second and fourth floors.

The retained order of the experimental can be determined as 4 . Then, to validate the efficiency of the time-delay compensation control method, the compensation controller with
GCC algorithm is applied to the experimental system. The performance of the compensation controller is compared with the system without time-delay. Time-delay assumed as $0.5 \mathrm{~s}$ in the control system is introduced by a time-delay block in the program modules. Under the above excitation load, the structural responses of different systems are shown in Figure 11, and the corresponding control effects and AMD parameters are listed in Table 7.

Figure 11 and Table 7 show that (1) the displacement and acceleration control effects of the system without compensation are all minus numbers, meaning that AMD system may increase the structural response and play a negative role when time-delay exists. (2) The control effects and AMD parameters of the system with GCC compensation are close to the system without time-delay. In particular, the maximum variations of the displacement and acceleration control effects between two different systems are only $1.7453 \%$ and $2.8189 \%$, and the AMD parameters of the controller with GCC compensation decrease by $1.8515 \mathrm{~N}$ and $0.0296 \mathrm{~m}$. Therefore, the compensation controller based on GCC algorithm can effectively compensate the long time-delay (e.g., $0.5 \mathrm{~s}$ in this paper) and suppress the structural response.

\section{Conclusions}

Time-delay has a negative influence in AMD control system. To address this issue, this paper presents a new reducedorder controller by improved BT method that can retain the abandoned high-order modal information of the original structure to reduce calculation time-delay. Time-delay compensation control gain designed by GCC algorithm is also 


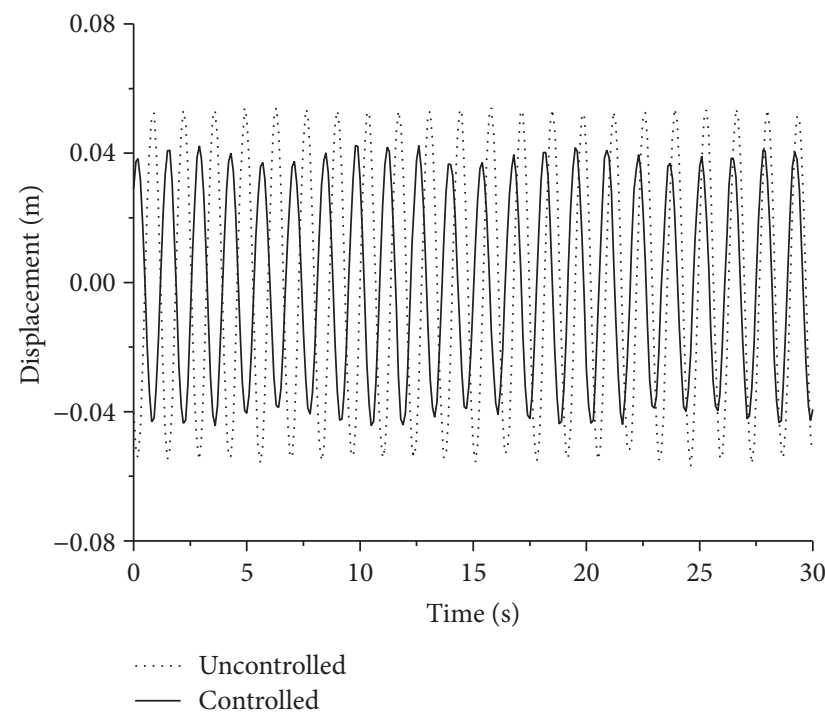

(a)

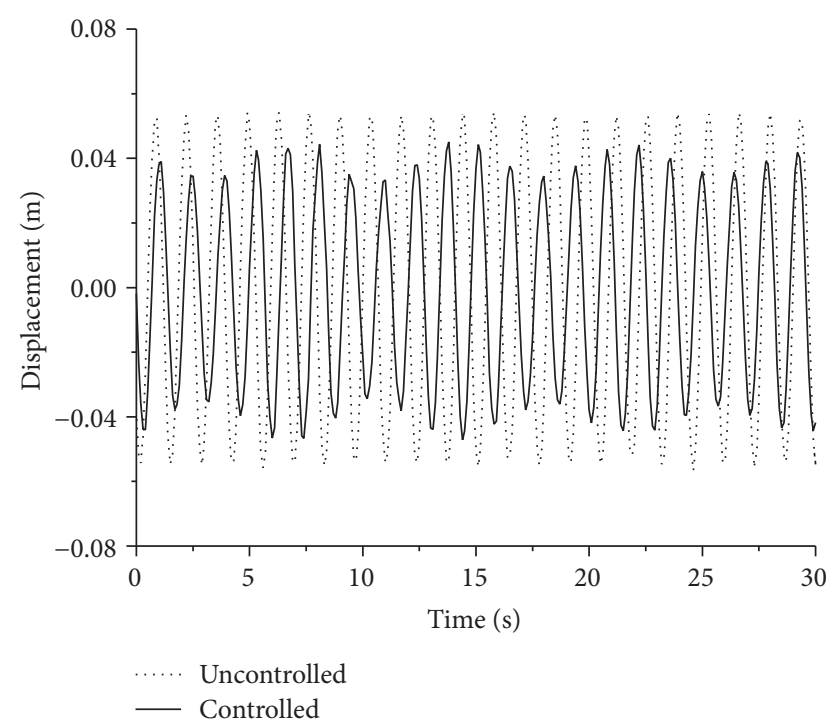

(c)

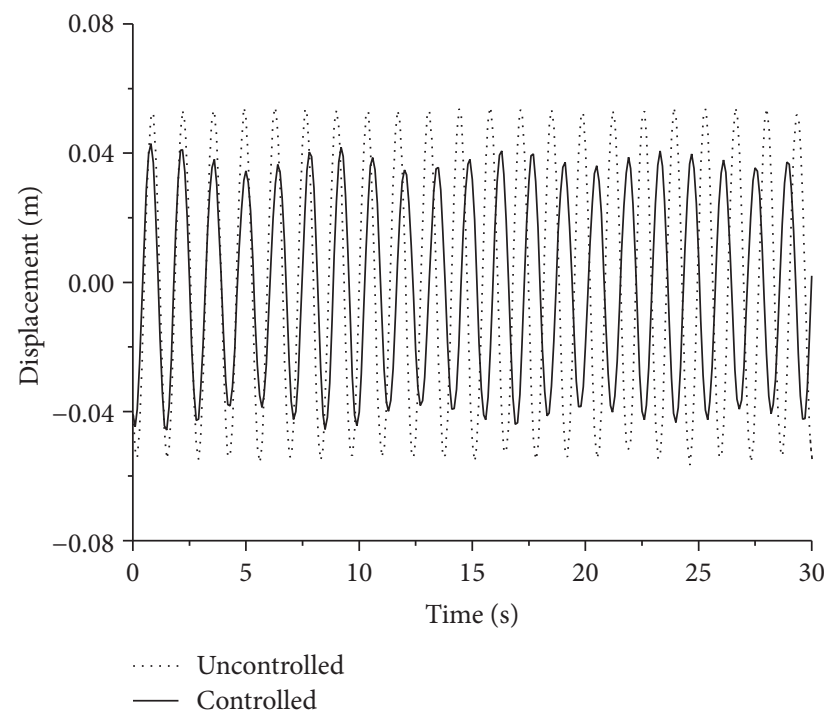

(b)

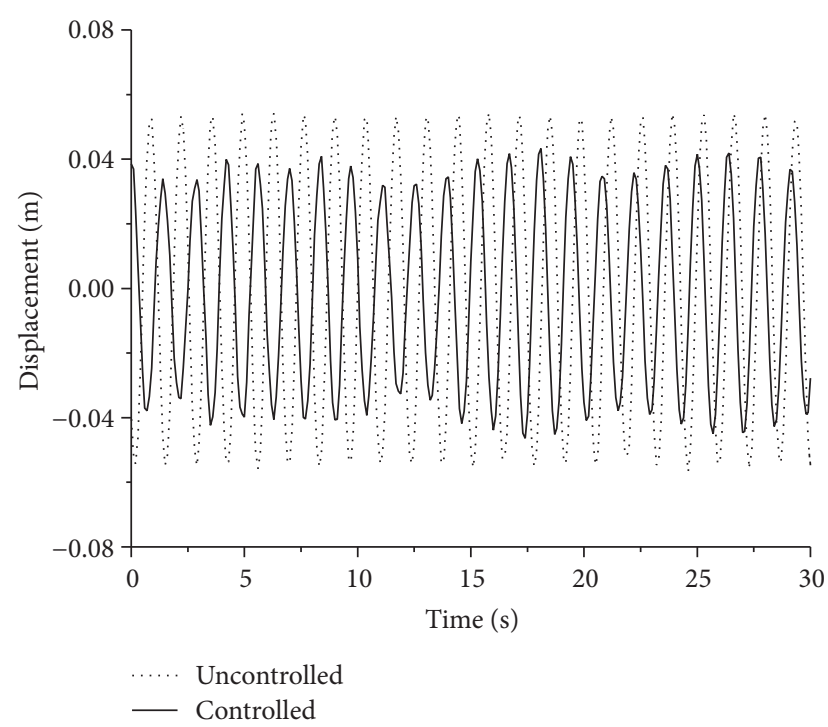

(d)

Figure 8: Comparison of displacement responses to 4th floor of the experimental system. (a) 4-order model, (b) 6-order model, (c) 8-order model, and (d) full-order model.

TABLE 6: Comparison of control effects of different control systems.

\begin{tabular}{|c|c|c|c|c|}
\hline Index & Full-order model (\%) & 4 -order model (\%) & 6-order model (\%) & 8 -order model (\%) \\
\hline \multicolumn{5}{|l|}{ Displacement (m) } \\
\hline 2nd floor & 24.8143 & 24.2223 & 24.4342 & 24.9452 \\
\hline 3rd floor & 25.5053 & 24.2089 & 24.8436 & 25.3991 \\
\hline 4th floor & 25.9376 & 24.5857 & 25.3514 & 25.8182 \\
\hline \multicolumn{5}{|l|}{ Acceleration $\left(\mathrm{m} / \mathrm{s}^{2}\right)$} \\
\hline 2nd floor & 66.2392 & 67.0423 & 62.5976 & 66.4737 \\
\hline 3rd floor & 59.7265 & 51.1551 & 53.8394 & 54.2685 \\
\hline 4th floor & 72.4474 & 68.9787 & 71.4552 & 68.7089 \\
\hline AMD control forces $(\mathrm{N})$ & 35.1827 & 35.0064 & 34.7217 & 34.9065 \\
\hline AMD strokes $(\mathrm{m})$ & 0.1985 & 0.2167 & 0.2114 & 0.1975 \\
\hline
\end{tabular}



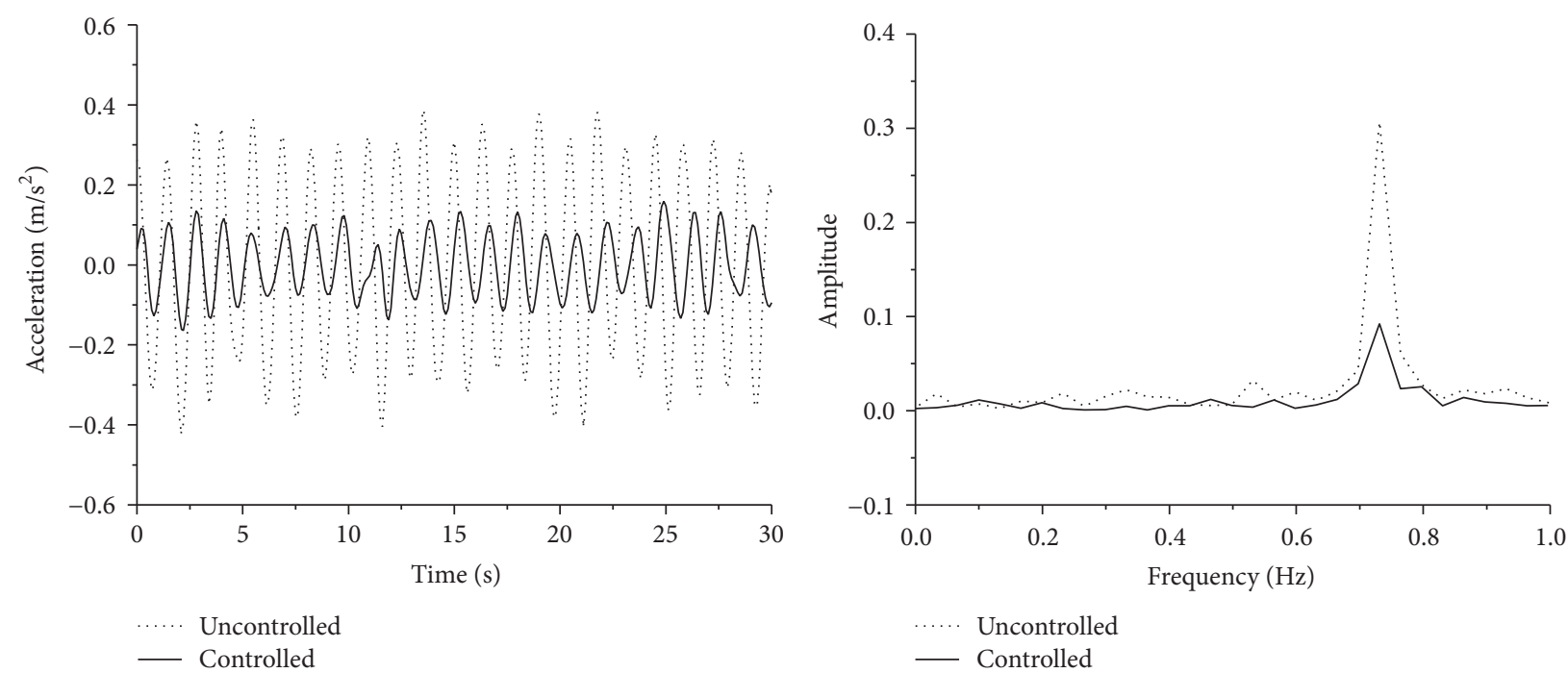

(a)

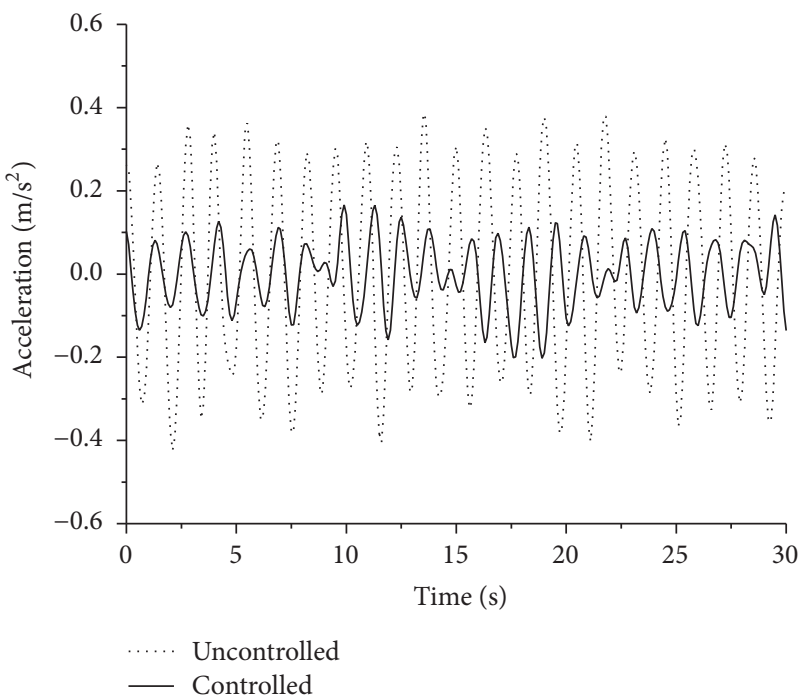

(c)

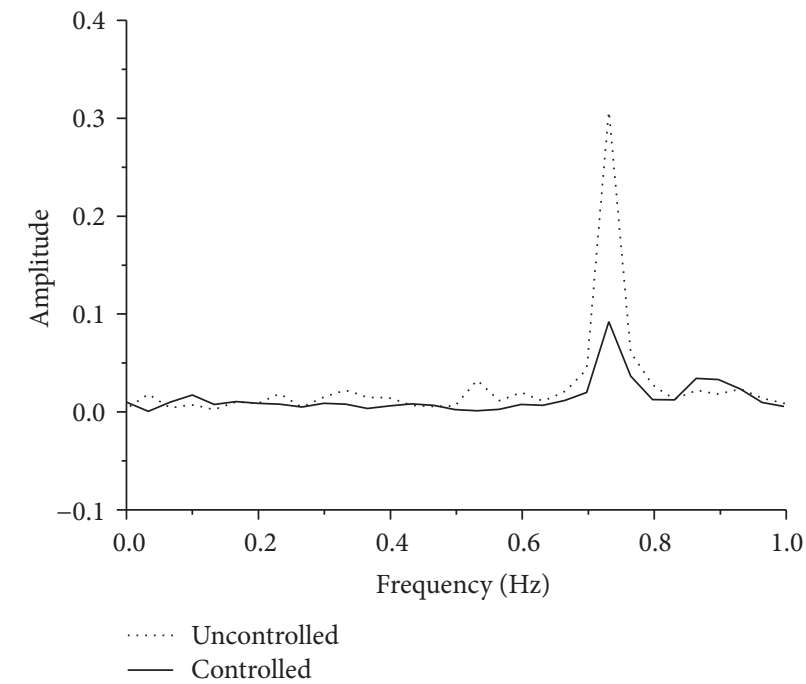

(d)
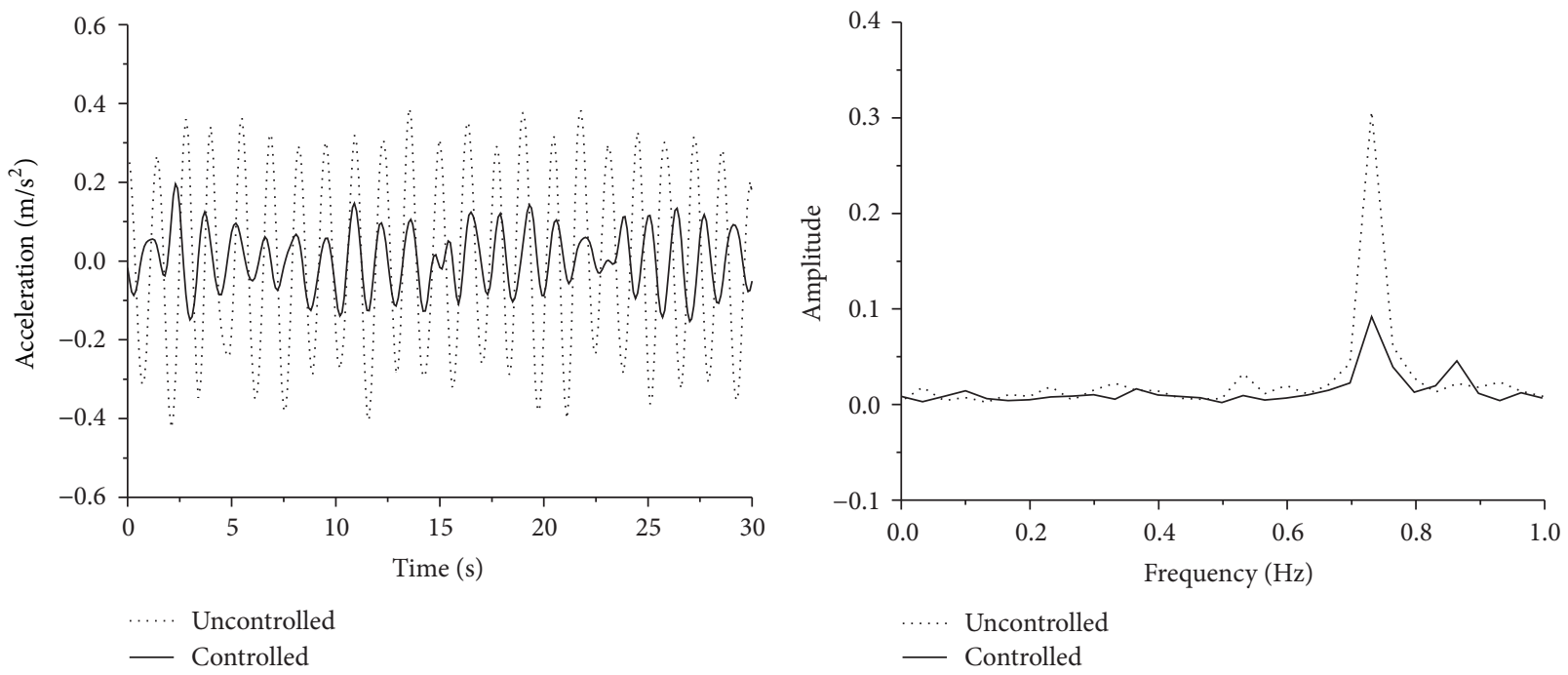

(e)

FIGURE 9: Continued. 


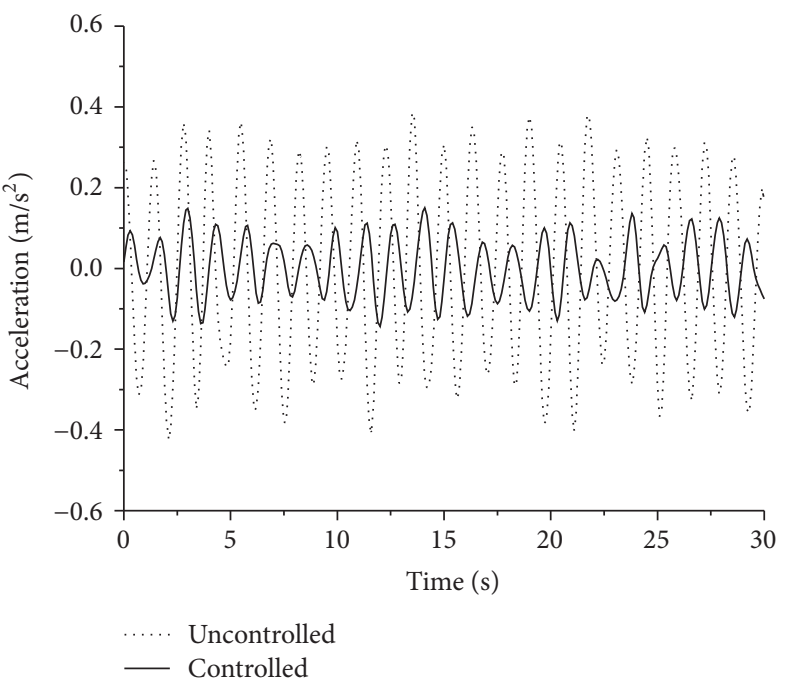

(g)

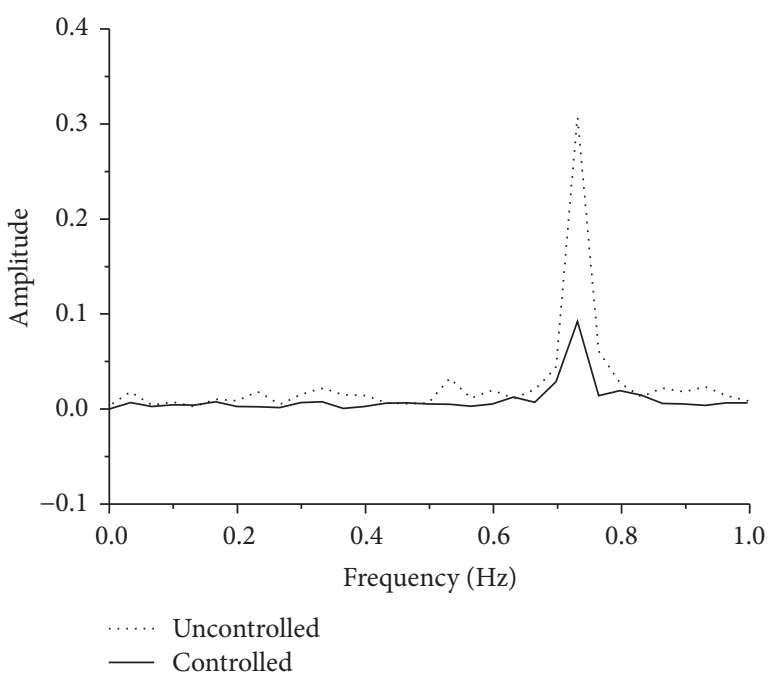

(h)

Figure 9: Comparison of acceleration responses to 4th floor of the experimental system. (a) and (b) 4-order model, (c) and (d) 6-order model, (e) and (f) 8-order model, and (g) and (h) full-order model.

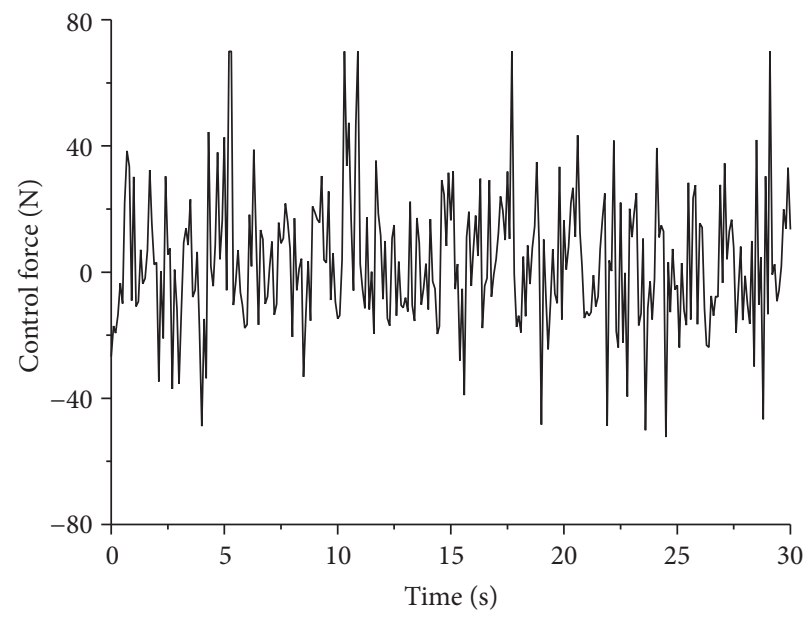

(a)

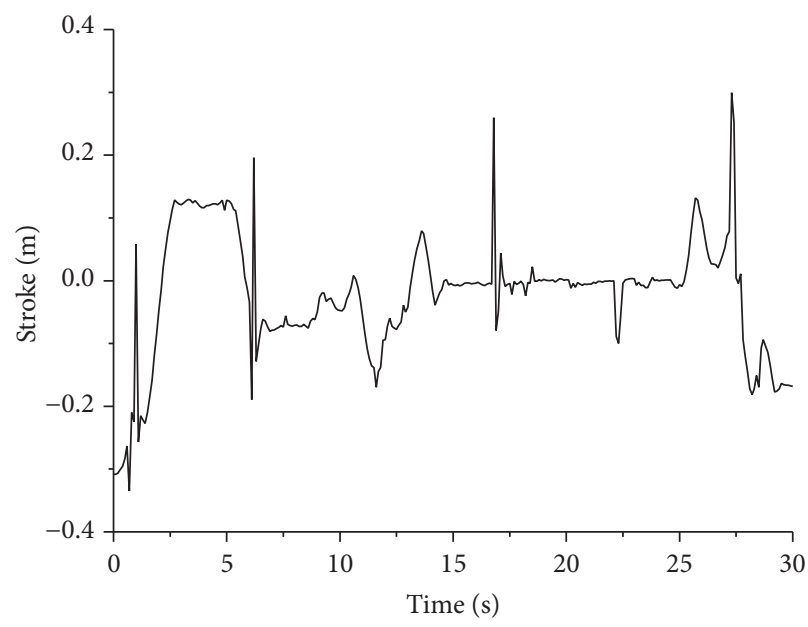

(b)

FIGURE 10: AMD parameters of the 4-order experimental system. (a) AMD control forces. (b) AMD strokes.

TABLE 7: Control effectiveness of structural responses (\%).

\begin{tabular}{|c|c|c|c|c|c|}
\hline \multirow{2}{*}{ Index } & \multirow{2}{*}{ No control } & \multicolumn{2}{|c|}{ No compensation } & \multicolumn{2}{|c|}{ GCC compensation } \\
\hline & & Responses & Effect (\%) & Responses & Effect (\%) \\
\hline \multicolumn{6}{|l|}{ Displacement (m) } \\
\hline 2nd floor & 0.0181 & 0.0191 & -5.5249 & 0.0136 & 24.8619 \\
\hline 3rd floor & 0.0262 & 0.0277 & -5.7252 & 0.0194 & 25.9542 \\
\hline 4th floor & 0.0301 & 0.0318 & -5.6478 & 0.0224 & 25.5814 \\
\hline \multicolumn{6}{|l|}{ Acceleration $\left(\mathrm{m} / \mathrm{s}^{2}\right)$} \\
\hline 2nd floor & 0.2267 & 0.2486 & -9.6603 & 0.0774 & 65.8580 \\
\hline 3rd floor & 0.2466 & 0.2656 & -7.7048 & 0.1135 & 53.9740 \\
\hline 4th floor & 0.2478 & 0.2683 & -8.2728 & 0.0700 & 71.7514 \\
\hline Peak control force $(\mathrm{N})$ & - & 33.7858 & - & 33.1549 & - \\
\hline Peak stroke $(\mathrm{m})$ & - & 0.1806 & - & 0.1871 & - \\
\hline
\end{tabular}




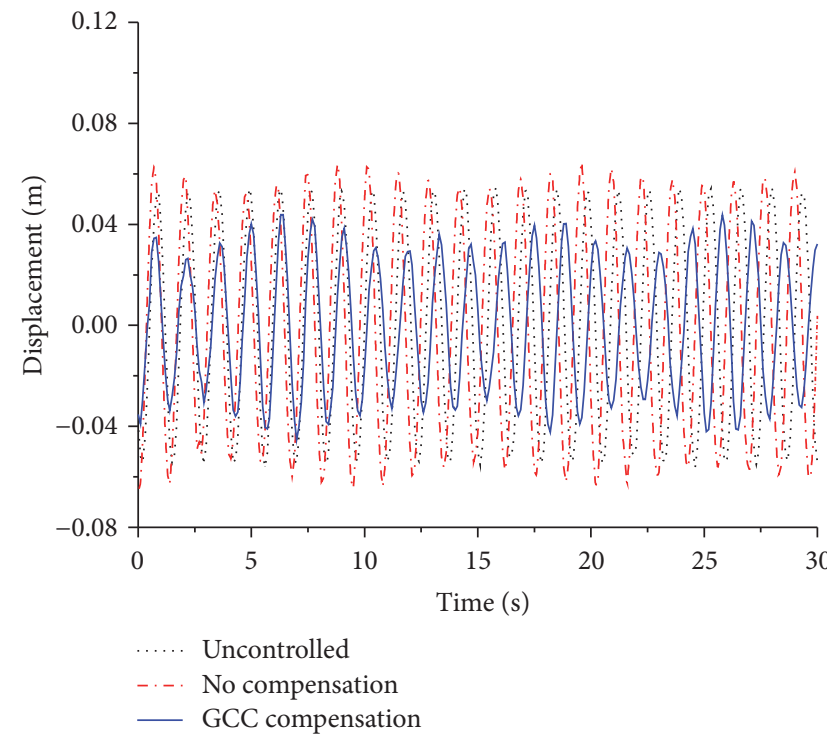

(a)

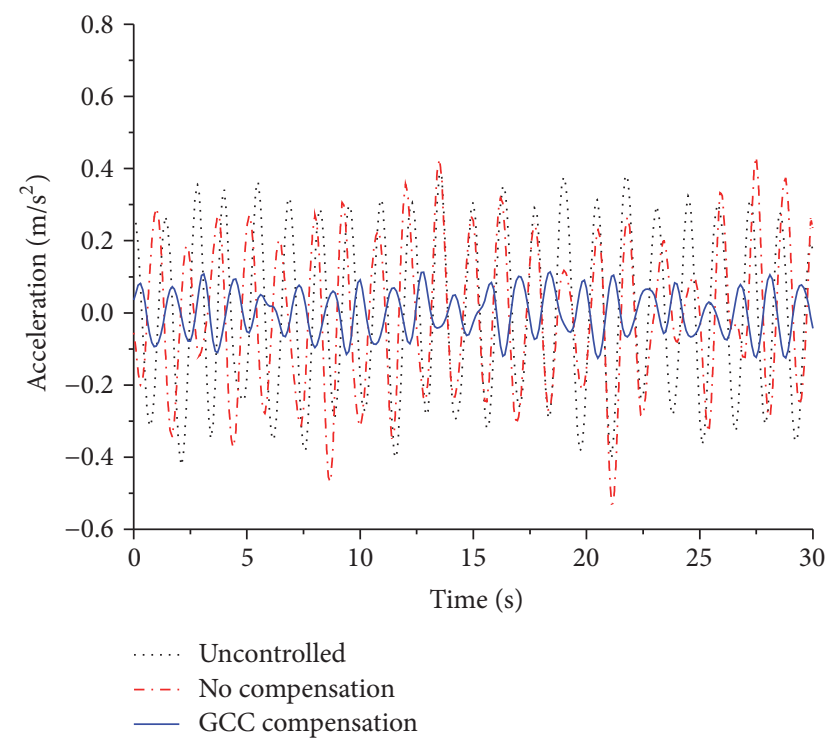

(b)

FIGURE 11: Comparison of structural responses to 4th floor of the experimental system under uncontrolled and controlled without compensation and with GCC compensation. (a) Displacement. (b) Acceleration.

presented to compensate data acquisition and actuator response time-delays. Finally, a numerical example and an experiment are presented to validate the effectiveness of the proposed method. Based on the results, the following conclusions can be drawn.

(1) The improved BT method presented in this paper can retain the abandoned structural high-order modal information; the acceleration transfer function of the reduced-order model by improved BT method is more consistent with the original model in low frequency than the model by classical BT method.

(2) As the modal mass participation ratio of a frame is larger than $90 \%$, the minimum retained order of its reduced-order controller by improved BT method can be obtained. Although the model reduction accuracy cannot meet the requirements of $90 \%$, this controller can still keep its control effects and AMD parameters stable.

(3) This new reduced-order controller whose order is reduced in maximum extent not only guarantees the performance of the system, but also effectively reduces calculation time of control force.

(4) The new reduced-order controller based on GCC algorithm in this paper can significantly improve the performance under the adverse influence of timedelay, and its performance is close to the classical control system without time-delay. As a result, it can effectively compensate time-delay and enhance the robustness of the control system.

\section{Competing Interests}

The authors declare that there is no conflict of interests regarding the publication of this paper.

\section{Acknowledgments}

The research described in this paper was financially supported by the National Key Research and Development Program of China (Grant no. 2016YFC0701102), the National Natural Science Foundations of China (Grants nos. 51378007 and 51538003), and the Shenzhen Technology Innovation Programs (Grants nos. JSGG20150330103937411 and JCYJ20150625142543473).

\section{References}

[1] H. Cao, A. M. Reinhorn, and T. T. Soong, "Design of an active mass damper for a tall TV tower in Nanjing, China," Engineering Structures, vol. 20, no. 3, pp. 134-143, 1998.

[2] M. Yamamoto, S. Aizawa, M. Higashino, and K. Toyama, "Practical applications of active mass dampers with hydraulic actuator," Earthquake Engineering and Structural Dynamics, vol. 30, no. 11, pp. 1697-1717, 2001.

[3] F. Ricciardelli, A. D. Pizzimenti, and M. Mattei, "Passive and active mass damper control of the response of tall buildings to wind gustiness," Engineering Structures, vol. 25, no. 9, pp. 11991209, 2003.

[4] B. Basu, O. S. Bursi, F. Casciati et al., "A European association for the control of structures joint perspective. Recent studies in civil structural control across Europe," Structural Control and Health Monitoring, vol. 21, no. 12, pp. 1414-1436, 2014. 
[5] F. E. Udwadia and P. Phohomsiri, "Active control of structures using time delayed positive feedback proportional control designs," Structural Control and Health Monitoring, vol. 13, no. 1, pp. 536-552, 2006.

[6] Y. Dong and F. Yang, "Stability analysis and observer design for a class of nonlinear systems with multiple time-delays," Advances in Difference Equations, vol. 2013, article no. 147, 2013.

[7] H. Sandberg, "A case study in model reduction of linear timevarying systems," Automatica, vol. 42, no. 3, pp. 467-472, 2006.

[8] G. Obinata and B. Anderson, Model Reduction for Control System Design, Springer, Vienna, Austria, 2001.

[9] Z.-Q. Qu, Y. Shi, and H. Hua, "A reduced-order modeling technique for tall buildings with active tuned mass damper," Earthquake Engineering and Structural Dynamics, vol. 30, no. 3, pp. 360-362, 2001.

[10] H. Du, J. Boffa, and N. Zhang, "Active seismic response control of tall Buildings based on reduced order model," in Proceedings of the American Control Conference, vol. 1-12, pp. 1132-1137, Minneapolis, Minn, USA, June 2006.

[11] B. C. Moore, "Principal component analysis in linear-systems: controllability, observability, and model-reduction," IEEE Transactions on Automatic Control, vol. 26, no. 1, pp. 17-32, 1981.

[12] S. Gugercin and A. C. Antoulas, "A survey of model reduction by balanced truncation and some new results," International Journal of Control, vol. 77, no. 8, pp. 748-766, 2004.

[13] Q. S. Li, "Reduced order control for wind-induced vibrations of tall buildings," Structural Design of Tall and Special Buildings, vol. 12, no. 2, pp. 177-190, 2003.

[14] J.-N. Yang, "Application of optimal control theory to civil engineering structures," Journal of the Engineering Mechanics Division, vol. 101, no. 6, pp. 819-838, 1975.

[15] S. Boyd, L. E. Ghaoui, E. Feron, and V. Balakrishnan, Linear Matrix Inequalities in System and Control Theory, Society for Industrial and Applied Mathematics (SIAM), Philadelphia, $\mathrm{Pa}$, USA, 1994.

[16] X. R. Mao, N. Koroleva, and A. Rodkina, "Robust stability of uncertain stochastic differential delay equations," Systems and Control Letters, vol. 35, no. 5, pp. 325-336, 1998.

[17] X. Mao, "Robustness of exponential stability of stochastic differential delay equations," IEEE Transactions on Automatic Control, vol. 41, no. 3, pp. 442-447, 1996.

[18] Y. Chen and A.-K. Xue, "Improved stability criterion for uncertain stochastic delay systems with nonlinear uncertainties," Electronics Letters, vol. 44, no. 7, pp. 458-459, 2008.

[19] W.-H. Chen, Z.-H. Guan, and X. Lu, "Delay-dependent exponential stability of uncertain stochastic systems with multiple delays: an LMI approach," Systems \& Control Letters, vol. 54, no. 6, pp. 547-555, 2005.

[20] S. Xu and T. Chen, "Robust $\mathrm{H}_{\infty}$ control for uncertain stochastic systems with state delay," IEEE Transactions on Automatic Control, vol. 47, no. 12, pp. 2089-2094, 2002.

[21] S. Y. Xu and T. W. Chen, " $H_{\infty}$ output feedback control for uncertain stochastic systems with time-varying delays," Automatica, vol. 40, no. 12, pp. 2091-2098, 2004.

[22] S. Xu, J. Lam, G.-H. Yang, and J. Wang, "Stabilization and $\mathrm{H}_{\infty}$ control for uncertain stochastic time-delay systems via nonfragile controllers," Asian Journal of Control, vol. 8, no. 2, pp. 197-200, 2006.

[23] H. Liu, G. Duan, and L. Fan, "Delay-dependent passive control of stochastic differential system with time delay," in Proceedings of the 8th World Congress on Intelligent Control and Automation (WCICA '10), pp. 963-968, Jinan, China, July 2010.
[24] S. S. Chang and T. K. Peng, "Adaptive guaranteed cost control of systems with uncertain parameters," IEEE Transactions on Automatic Control, vol. 17, no. 4, pp. 474-483, 1972.

[25] X.-P. Guan and C.-L. Chen, "Delay-dependent guaranteed cost control for T-S fuzzy systems with time delays," IEEE Transactions on Fuzzy Systems, vol. 12, no. 2, pp. 236-249, 2004.

[26] B. Chen and X. P. Liu, "Fuzzy guaranteed cost control for nonlinear systems with time-varying delay," IEEE Transactions on Fuzzy Systems, vol. 13, no. 2, pp. 238-249, 2005.

[27] M. Ikeda and T. Ashida, "Stabilization of linear system with time-varying delay," IEEE Transactions on Automatic Control, vol. 24, no. 2, pp. 369-370, 1979.

[28] E. Cheres, Z. J. Palmor, and S. Gutman, "Quantitative measures of robustness for systems including delayed perturbations," IEEE Transactions on Automatic Control, vol. 34, no. 11, pp. 1203-1204, 1989.

[29] H. S. Wu and K. Mizukami, "Robust stabilization of uncertain linear dynamical systems with time-varying delay," Journal of Optimization Theory and Applications, vol. 82, no. 3, pp. 593606, 1994.

[30] S. Moheimani and I. R. Petersen, "Optimal quadratic guaranteed cost control of a class of uncertain time-delay systems," IEE Proceedings-Control Theory and Applications, vol. 144, no. 2, pp. 183-188, 1997.

[31] C. Qu, L. Huo, and H. Li, "Fault tolerant control for civil structures based on LMI approach," Mathematical Problems in Engineering, vol. 2013, Article ID 762385, 8 pages, 2013.

[32] A. J. Laub, M. T. Heath, C. C. Paige, and R. C. Ward, "Computation of system balancing transformations and other applications of simultaneous diagonalization algorithms," IEEE Transactions on Automatic Control, vol. 32, no. 2, pp. 115-122, 1987.

[33] AASHTO, AASHTO LRFD Bridge Design Specifications, American Association of State Highway and Transportation Officials, Washington, DC, USA, 5th edition, 2012.

[34] Caltrans, Caltrans Seismic Design Criteria Version 1.7, Califionia Department of Transportation, Sacramento, Calif, USA, 2013.

[35] S. Sastry, Lyapunov Stability Theory, Springer, New York, NY, USA, 1999.

[36] F. Zhang, Ed., The Schur Complement and its Applications, vol. 4 of Numerical Methods and Algorithms, Springer-Verlag, 2005.

[37] R. W. Clough and J. Penzien, Dynamics of Structures, McGrawHill, New York, NY, USA, 1975.

[38] E. J. Hannan, "The identification of vector mixed autoregressive-moving average system," Biometrika, vol. 56, no. 1, pp. 223225, 1969.

[39] J. Teng, H. B. Xing, W. Lu, Z. H. Li, and C. J. Chen, "Influence analysis of time delay to active mass damper control system using pole assignment method," Mechanical Systems and Signal Processing, vol. 80, pp. 99-116, 2016. 


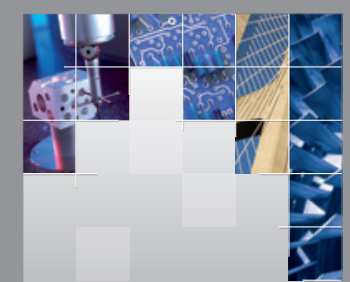

\section{Enfincering}
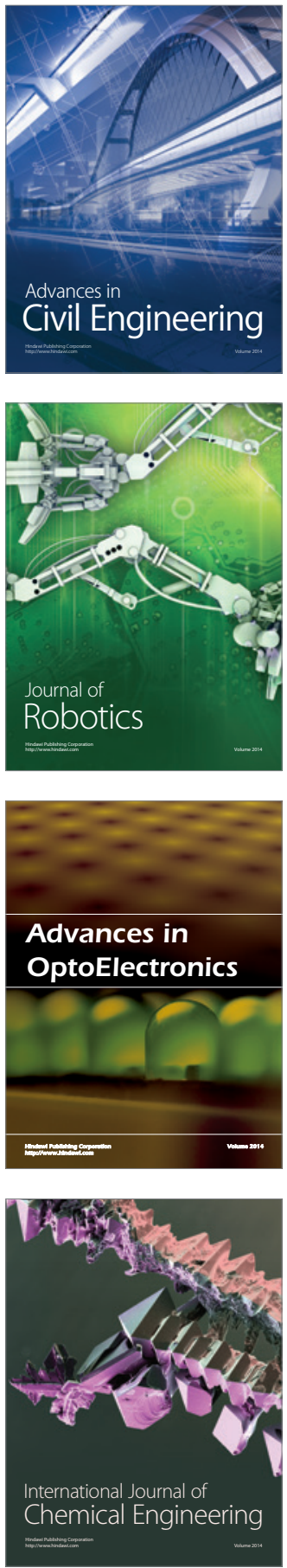

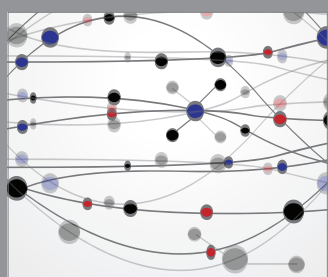

The Scientific World Journal

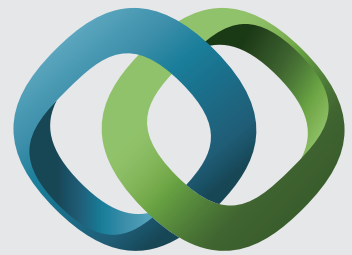

\section{Hindawi}

Submit your manuscripts at

https://www.hindawi.com
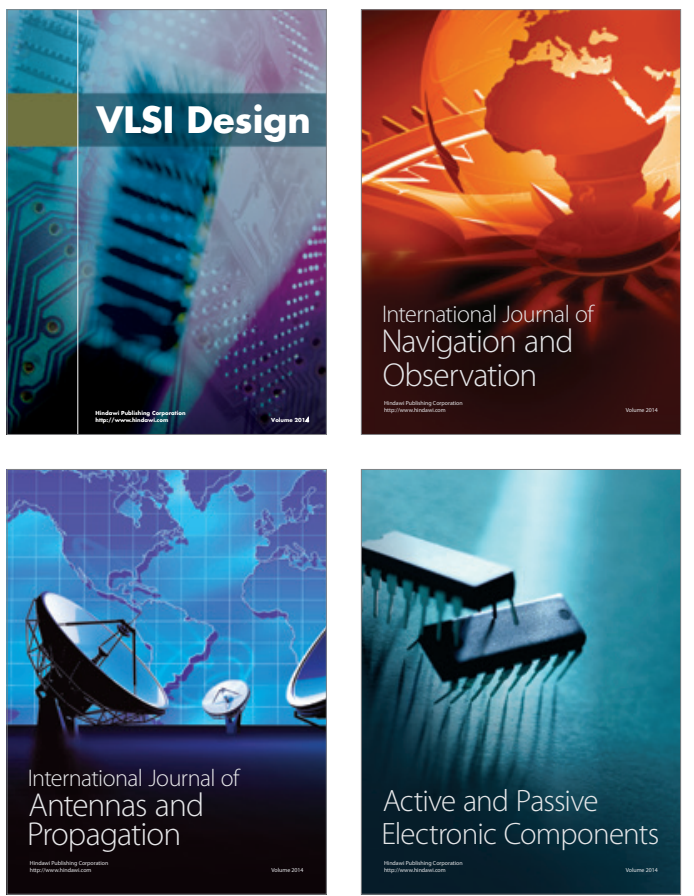
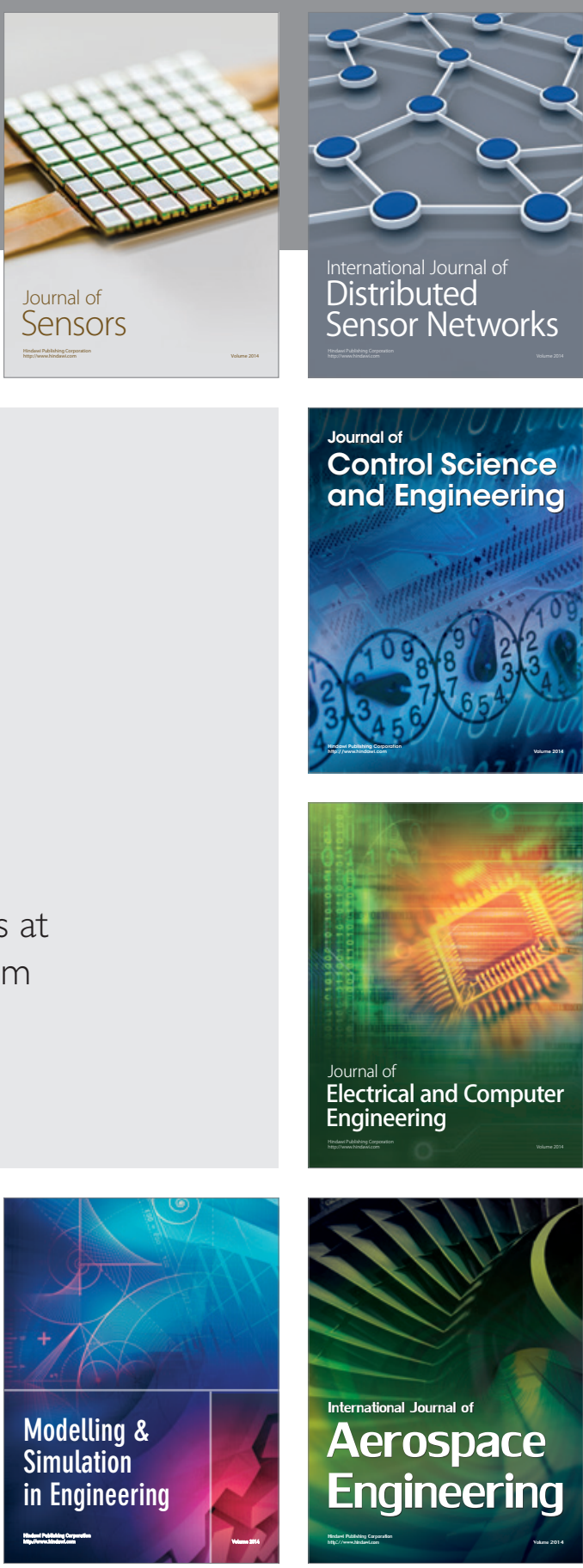

International Journal of

Distributed

Sensor Networks

$-$

Joumal of

Control Science

and Engineering
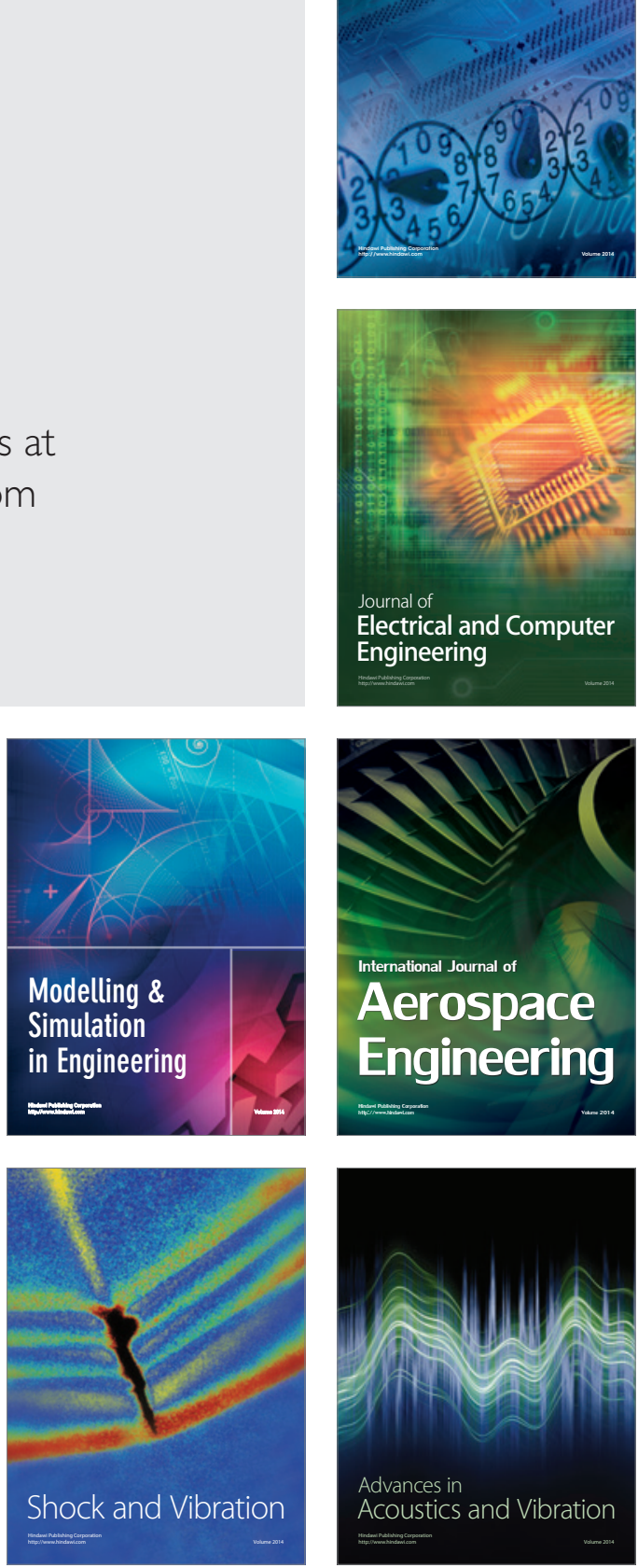